\title{
miR-126a-5p-Dbp and miR-31a-Crot/Mrpl4 interaction pairs crucial for the development of hypertension and stroke
}

\author{
QINI ZHAO ${ }^{1-3}$, HUAN SUN $^{1,2}$, LIQUAN YIN $^{4}$ and LIBO WANG ${ }^{5}$ \\ ${ }^{1}$ Department of Cardiology, ${ }^{2}$ Jilin Provincial Key Laboratory for Genetic Diagnosis of Cardiovascular Disease, \\ ${ }^{3}$ Jilin Provincial Engineering Laboratory for Endothelial Function and Genetic Diagnosis of \\ Cardiovascular Disease, Departments of ${ }^{4}$ Rehabilitation Medicine and ${ }^{5}$ Neurology, \\ China-Japan Union Hospital of Jilin University, Changchun, Jilin 130033, P.R. China
}

Received May 14, 2019; Accepted July 19, 2019

DOI: $10.3892 / \mathrm{mmr} .2019 .10679$

\begin{abstract}
The present study aimed to integrate the mRNA and microRNA (miRNA) expression profiles of spontaneously hypertensive rats (SHR rats) and stroke-prone spontaneously hypertensive rats (SHRSP rats) to screen for potential therapeutic targets for hypertension and stroke. The datasets GSE41452, GSE31457, GSE41453 and GSE53363 were collected from the Gene Expression Omnibus (GEO) database to screen differentially expressed genes (DEGs). The GSE53361 dataset was obtained to analyze differentially expressed miRNAs (DEMs). The DEGs and DEMs were identified between SHR (or SHRSP) rats and normotensive Wistar-Kyoto (WKY) rats using the Linear Models for Microarray (limma) data method. Venn diagrams were used to show the SHR-specific, SHRSP-specific and SHR-SHRSP shared DEGs and DEMs, and these were utilized to construct the protein-protein interaction (PPI) and miRNA-mRNA regulatory networks. The Database for Annotation, Visualization and Integrated Discovery (DAVID) was used to explore the function of the genes. Subsequently, the connectivity Map (CMAP) database was searched to identify small-molecule drugs. Comparisons between the GSE41452-GSE31457-GSE41453 merged and GSE53363 datasets identified 2 SHR-specific, 8 SHRSP-specific and 15 SHR-SHRSP shared DEGs. Function enrichment analysis showed that SHRSP-specific D-box binding PAR bZIP transcription factor ( $D b p$ ) was associated with circadian rhythm, and SHR-SHRSP shared carnitine O-octanoyltransferase (Crot) was involved in fatty acid metabolic processes or the inflammatory response via interacting with epoxide hydrolase 2 (EPHX2). SHR-SHRSP
\end{abstract}

Correspondence to: Dr Libo Wang, Department of Neurology, China-Japan Union Hospital of Jilin University, 126 Xiantai Street, Erdao, Changchun, Jilin 130033, P.R. China

E-mail: wang_libo@jlu.edu.cn

Key words: stroke-prone spontaneously hypertensive rats, miRNA, small molecular drug, circadian rhythm, inflammation, angiogenesis shared mitochondrial ribosomal protein L4 (Mrpl4) may exert roles by interacting with the threonine-tRNA ligase, TARS2. The miRNA regulatory network predicted that upregulated Dbp could be regulated by rno-miR-126a-5p, whereas downregulated Crot and Mrpl4 could be modulated by rno-miR-31a. The CMAP database predicted that small-molecule drugs, including botulin, Gly-His-Lys, and podophyllotoxin, may possess therapeutic potential. In conclusion, the present study has identified Dbp, Crot and Mrpl4 as potential targets for the treatment of hypertension and stroke. Furthermore, the expression of these genes may be reversed by the above miRNAs or drugs.

\section{Introduction}

Hypertension, defined as systolic blood pressure (BP) $\geq 140 \mathrm{mmHg}$ or diastolic BP $\geq 90 \mathrm{mmHg}$, has been a longstanding and common chronic disease in modern society due to the improvements in people's living standards and changes in their lifestyles (1). Sustained hypertension is an important risk factor for the development of cardiovascular disorders, such as transient ischemic attacks or stroke (2-4), which is the leading cause of death worldwide $(5,6)$, imposing a heavy economic burden on family and society (7). Therefore, how to prevent hypertension-associated stroke has become a major public health problem.

Spontaneously hypertensive rats (SHR) and stroke-prone spontaneously hypertensive rats (SHRSP) are widely used animal models for studying the molecular mechanisms of severe hypertension and associated stroke (8) to provide potential therapeutic strategies (9). Previous studies have utilized high-throughput microarray technology to investigate gene expression in the brain (10), adrenal gland (11), kidneys (12), mesenteric artery (13) and liver (14) of SHR and SHRSP rats compared with the normotensive control strain, Wistar-Kyoto (WKY) rats. In these studies, obvious overlaps were identified in different tissue samples as SHRSP-specific genes, including angiotensinogen (Agt), which was found to be crucial for SHRSP in the adrenal gland (11) and kidneys (12), and angiotensin II receptor-associated protein (Agtrap), which was found to be crucial for SHRSP in the brain (10) and kidneys (12). These analyses indicated the common genes that may be 
underlying targets for treatment of hypertension-associated stroke. However, to the best of the authors' knowledge, no studies have been performed to date to investigate the shared genes in all studied samples previously.

Furthermore, increasing evidence has reported that microRNAs (miRNAs), small non-coding RNA molecules of 18-25 nucleotides in length, are also essential in the development of hypertension and associated stroke. They function by negatively regulating the expression of their target genes at the post-transcriptional level. For example, Rubattu et al (15) demonstrated that uncoupling protein 2 (UCP2)-targeted rno-miR-503 was significantly upregulated in the brain of SHRSP rats. Downregulation of miR-503 level protected SHRSP from stroke occurrence. In vitro overexpression of miRNA-503 in endothelial cells suppressed UCP2 expression and led to a significant increase in cell mortality, with decreased cell viability (15). Matsuoka et al (16) observed that the miR-124 level was markedly lower in brains of SHRSP compared with WKY rats, whereas claudin domain-containing 1 (Cldnd1) mRNA and protein levels were significantly higher. Human brain endothelial cells transfected with a miR-124 mimic exhibited a significantly decreased mRNA expression level of Cldnd1 (16). However, the mechanism underpinning miRNA-mRNA interaction for SHRSP rats has yet to be fully elucidated (13).

The present study aimed to further screen for crucial miRNA-mRNA interactions in order to explain the etiology of SHRSP, and to explore novel treatment modalities by integrating all the mRNA and miRNA expression profiles associated with SHRSP that were obtained from the public databases using a serial of bioinformatic methods.

\section{Materials and methods}

Collection of microarray data. The microarray datasets of SHRSP were available at the National Center for Biotechnology Information (NCBI) Gene Expression Omnibus (GEO) database (http://www.ncbi.nlm.nih. gov/geo/). The GSE41452 (10), GSE31457 (11) and GSE41453 datasets (12) were analyzed by the research team of Watanabe et al (12) to respectively investigate the mRNA expression profiles in whole brains, adrenal glands and kidneys of 3 rat strains: Normotensive WKY, SHR, and SHRSP, at 3 and 6 weeks of age. GSE53363 and GSE53361 datasets were provided by Palao et al (13) to respectively analyze the mRNA and miRNA expression profiles in mesenteric arteries of normotensive WKY (including 3 sublines, WKY/NCrl, WKY/NHsd, WKY/NTac), SHR (including 2 sublines, SHR/NCrL and SHR/NHsd) and SHRSP rats at 6 weeks and 5 months of age. The characteristics of the microarray datasets are shown in Table I.

Differential expression analysis. The normalized series matrix files of each dataset were downloaded from GEO. Data from the GSE41452, GSE31457 and GSE41453 datasets were merged into one in order to use the same model samples. The series matrix data were extracted and quantile-normalized using the Linear Models for Microarray Data (Limma) package (version 3.38.3; https://bioconductor. org/packages/release/bioc/html/limma.html) in $\mathrm{R}$ (version 3.5.2; http://www.R-project.org/) (17). The differentially expressed genes (DEGs) and miRNAs (DEMs) between SHR (or SHRSP) and WKY were identified using the Limma empirical Bayes analysis pipeline. P-values were adjusted to the false discovery rate (FDR) using Benjamini and Hochberg multiple testing (18). DEGs and DEMs were defined as $\mid \log 2$ fold change $(\mathrm{FC}) \mid>0.5$ and $\mathrm{P}<0.05$, since the number of DEGs and DEMs would be fewer if FDR were to be considered, which may have been disadvantageous in terms of performing the following analyses. Hierarchical clustering of DEGs and DEMs, with results visualized as heat-maps, was performed using the pheatmap package (version 1.0.8; https://cran.r-project.org/web/packages/pheatmap) based on Euclidean distances. Venn diagrams (http://bioinformatics.psb.ugent.be/webtools/Venn/) were drawn to obtain the DEGs that were SHR-specific, SHRSP-specific and SHR-SHRSP shared, respectively, in two datasets (GSE41452-GSE31457-GSE41453 and GSE53363), as well as genes common to both datasets.

Protein-protein interaction (PPI) network. All genes for SHR-specific, SHRSP-specific and SHR-SHRSP shared in the two datasets were used for constructing the PPI network to reveal the possible interaction mechanisms of common DEGs. Underlying PPI associations were collected from the Search Tool for the Retrieval of Interacting Genes database, version 10.0 (STRING; http://string db.org/) (19), which is a comprehensive database that provides $>200$ million interactions among 5 million proteins, including experimental, predicted, transferred and text-mining interactions. Only interaction pairs with a combined score $>0.4$ (medium confidence) were used to establish the PPI network, and this was accomplished using Cytoscape software (version 3.4.0; www.cytoscape.org/) (20).

miRNA-target gene regulatory network. The target genes of DEMs were predicted using the miRwalk database (version 2.0; http: //www.zmf.umm.uni-heidelberg. de/apps/zmf/mirwalk2) (21), which is a comprehensive database for integrating the predicted results of 12 algorithms (miRWalk, Microt4, miRanda, mirbridge, miRDB, miRMap, miRNAMap, Pictar2, PITA, RNA22, RNAhybrid and Targetscan). Subsequently, the target genes of DEMs that were predicted by at least 5 of the databases were overlapped with the common DEGs in two datasets to obtain potentially new negative expression associations between DEMs and DEGs, and this procedure was followed to construct the miRNA-target gene regulatory network using Cytoscape software (20).

Function enrichment analysis. Kyoto Encyclopedia of Genes and Genomes (KEGG) pathway and Gene Ontology (GO) [including the categories of 'biological process' (BP), 'molecular function' (MF) and 'cellular component' (CC)] enrichment analyses were performed to explore the underlying functions of the DEGs in the SHR-specific, SHRSP-specific and SHR-SHRSP shared PPI networks, as well as the miRNA-mRNA network, The Database for Annotation, Visualization and Integrated Discovery 
Table I. Microarray datasets collected from the GEO database.

\begin{tabular}{lcclcccc}
\hline \multirow{2}{*}{$\begin{array}{l}\text { Accession } \\
\text { number }\end{array}$} & Type & & \multicolumn{1}{c}{ Sample size } & \\
\cline { 4 - 6 } GSE41452 & mRNA & GPL14745 & $\begin{array}{l}\text { Agilent-028282 Whole Rat Genome } \\
\text { microarray 4x44K v3 }\end{array}$ & 6 & 6 & 6 & Whole brains \\
GSE31457 & mRNA & GPL14745 & $\begin{array}{l}\text { Agilent-028282 Whole Rat Genome } \\
\text { microarray 4x44K v3 }\end{array}$ & 6 & 6 & 6 & Adrenal glands \\
GSE41453 & mRNA & GPL14745 & $\begin{array}{l}\text { Agilent-028282 Whole Rat Genome } \\
\text { microarray 4x44K v3 }\end{array}$ & 6 & 6 & 6 & Kidneys \\
GSE53363 & mRNA & GPL15084 & $\begin{array}{l}\text { Agilent-028279 SurePrint G3 Rat } \\
\text { GE 8x60K microarray } \\
\text { Agilent-046066 Unrestricted Rat }\end{array}$ & 6 & 4 & 2 & Mesenteric artery \\
GSE53361 & miRNA & GPL18115 & 6 & 6 & 4 & Mesenteric artery \\
\hline
\end{tabular}

WKY, Wistar-Kyoto; SHR, spontaneously hypertensive rats; SHRSP, stroke-prone spontaneously hypertensive rats; GEO, Gene Expression Omnibus.

(DAVID) (version 6.8; http://david.abcc.ncifcrf.gov) (22). $\mathrm{P}<0.05$ was considered to indicate a statistically significant value.

Screening of small-molecule drugs. To better identify potential therapeutic drugs for treatment of SHRSP, the common DEGs (upregulated or downregulated) in two datasets were queried using the Connectivity Map online tool (version 2.0; https://portals.broadinstitute.org/cmap/) (23). The query small molecules were output with a connectivity score from +1 to -1 . Small-molecule drugs may be therapeutic when their connectivity scores are near to -1 ; by contrast, small-molecule drugs may actually induce the disease if their connectivity scores are near to +1 . Candidate small-molecule drugs were identified with a P-value $<0.05$ and a Iconnectivity scorel $\geq 0.8$.

\section{Results}

Differential expression analysis. In the merged dataset (GSE31457-GSE41452-GSE41453), a total of 366 DEGs were identified between SHR and WHY rats, including 177 upregulated and 189 downregulated DEGs. Three hundred and ninety-three DEGs were screened between SHRSP and WHY, including 151 upregulated and 242 downregulated DEGs. Venn diagrams revealed that 75 upregulated DEGs were SHR-specific, 49 were SHRSP-specific, and 102 were SHR-SHRSP shared; for the downregulated DEGs, 44 were SHR-specific, 97 were SHRSP-specific, and 145 were SHR-SHRSP shared (Fig. 1A).

In the GSE53363 dataset, a total of 246 DEGs were identified between SHR and WHY, including 145 upregulated and 101 downregulated DEGs, whereas 480 DEGs were screened between SHRSP and WHY, including 300 upregulated and 180 downregulated DEGs. Venn diagrams revealed that 55 upregulated DEGs were SHR-specific, 210 were SHRSP-specific, and 90 were SHR-SHRSP shared; for the downregulated DEGs, 44 were SHR-specific, 123 were SHRSP-specific and 57 were SHR-SHRSP shared (Fig. 1A).

In the GSE53361 dataset, a total of 11 DEMs were identified between SHR and WHY, including 5 upregulated and 6 downregulated DEMs; 13 DEMs were screened between SHRSP and WHY, including 6 upregulated and 7 downregulated DEMS (Table II). Venn diagrams revealed that 2 upregulated DEMs were SHR-specific (rno-miR-146b-5p and rno-miR-132-3p), whereas 3 were SHRSP-specific (rno-miR-196b-5p, rno-miR-21-5p and rno-miR-196a-5p) and 3 were SHR-SHRSP shared (rno-miR-31a-5p, rno-miR-31a-3p and rno-miR-511-3p). For the downregulated DEMs, 2 were SHR-specific (rno-miR-3593-3p and rno-miR-150-3p), 3 were SHRSP-specific (rno-miR-126a-5p, rno-miR-126a-3p and rno-miR-483-3p), and 4 were SHR-SHRSP shared (rno-miR-1224, rno-miR-146a-5p, rno-miR-672-5p and rno-miR-150-5p) (Fig. 1A). Among these DEMs, rno-miR-31a-3p and rno-miR-31a-5p may be especially important, since their FDR was $<0.05$ (Table II).

Subsequently, the merged and GSE53363 datasets were compared. This analysis identified 2 SHR-specific DEGs [cholesterol 25-hydroxylase (Ch25h) and SEC16 homolog B, endoplasmic reticulum export factor (Sec16b)], 8 SHRSP-specific DEGs (7 with consistent expression in the two datasets RGD1310414, phosphatidylinositol glycan anchor biosynthesis, class Z (Pigzl1), nuclear receptor subfamily 1, group D, member 2 (Nr1d2), Tef, LOC686388, D-box binding PAR bZIP transcription factor (Dbp) and transforming growth factor $\beta$ induced (Tgfbi); and one gene with differing expression [Myoglobin (Mb)] \} and 15 SHR-SHRSP shared DEGs (14 with consistent expression between the two datasets: (aldehyde dehydrogenase 5 family, member A1 (Aldh5a1), transmembrane protein 243 (RGD1562351), zinc finger protein 597 (Zfp597), endonuclease G (Endog), membrane-spanning 4-domains A6A (Ms4a11), torsin family 1 member B (Torlb), retinol saturase (Retsat), carnitine O-octanoyltransferase (Crot), FKBP prolyl isomerase 
A
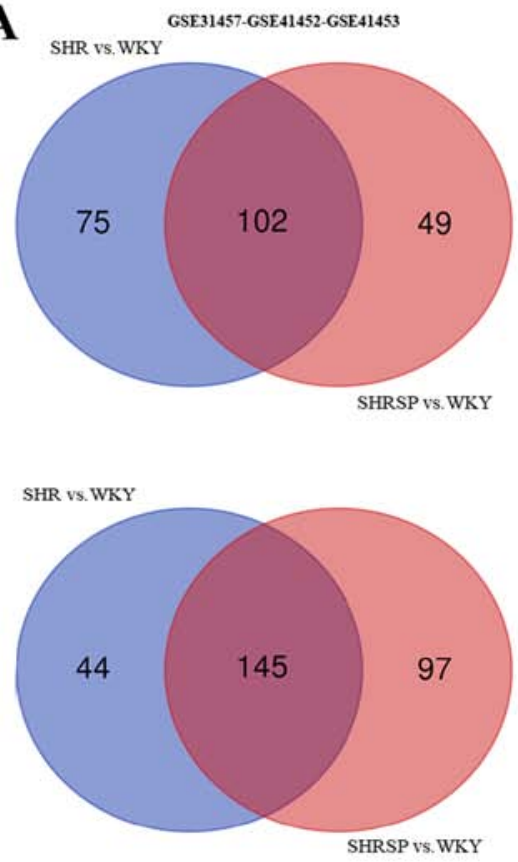

B

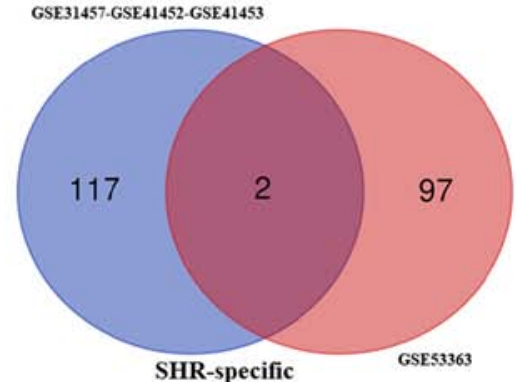

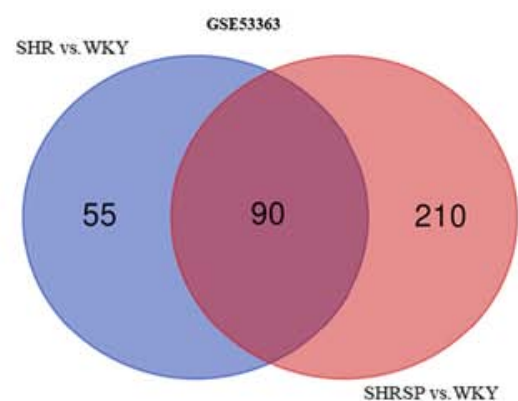
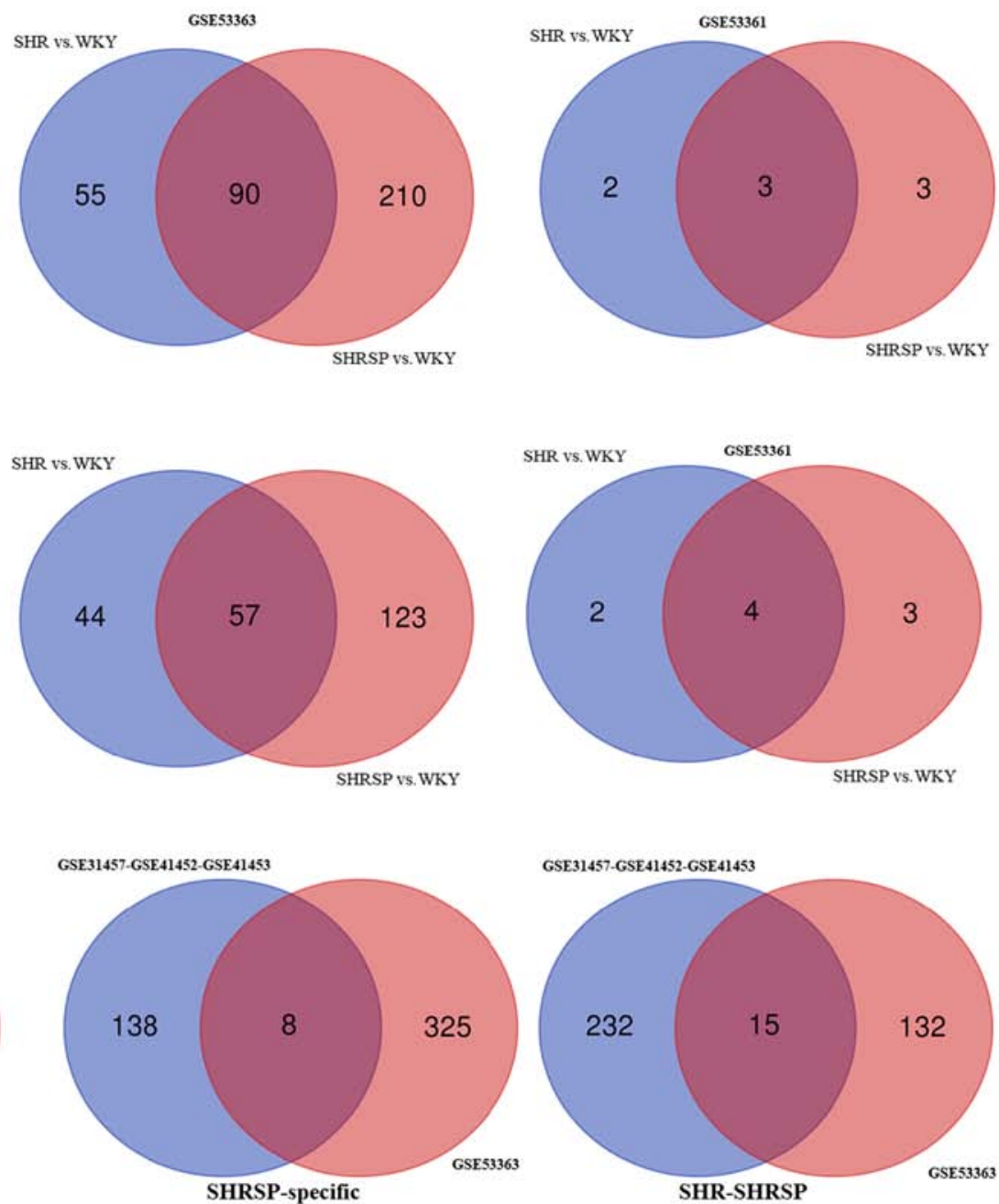

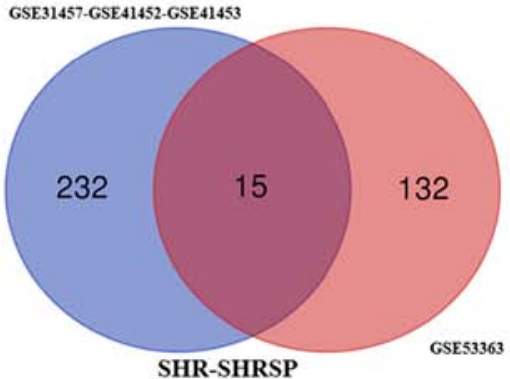

Figure 1. Venn diagrams to display the SHR-specific, SHRSP-specific and SHR-SHRSP shared differentially expressed genes or miRNAs. (A) Comparison of DEGs or miRNAs between SHR and SHRSP in three datasets (i.e., GSE31457-GSE41452-GSE41453, GSE53363 and GSE53361). The upper panel shows the upregulated DEGs, whereas the lower panel shows the DEGs that were downregulated. (B) Comparison of DEGs between two datasets. DEG, differentially expressed gene; SHR, spontaneously hypertensive rats; SHRSP, stroke-prone spontaneously hypertensive rats; WKY, Wistar-Kyoto.

(5Fkbp5), charged multivesicular body protein 1B (Chmplb), mitochondrial ribosomal protein L4 (Mrpl4), threonyl-tRNA synthetase 2, mitochondrial (Tars2), RIO kinase 1 (Riok1) and transmembrane protein 14A (Tmem14a); and one gene with differing expression [Peroxisomal membrane protein 4 (Pxmp4)]\} that were common in these two datasets (Fig. 1B; Table III). Among these DEGs, Torlb and Mrpl4 may be especially important, since their FDR was $<0.05$ in all datasets as well as SHR and SHR-SP (Table III).

The expression of common DEGs in the GSE31457-GSE41452-GSE41453 (Fig. 2A) and GSE53361 (Fig. 2B) datasets, and all DEMs in the GSE53361 dataset (Fig. 2C) in the three sample groups, are shown in the heat-map.

PPI network and function enrichment analyses. PPI networks were respectively constructed for SHR-specific, SHRSP-specific and SHR-SHRSP shared DEGs by uniting the DEGs in two datasets due to the small number of common DEGs (Fig. 2). As a result, 123 interaction pairs between 115 DEGs (for example, Sec16b-Ccdc92) were obtained for the SHR-specific group (Fig. 3); 828 interaction pairs between 345 DEGs (for example, Mb-Hsph1) were obtained for the SHRSP-specific group (Fig. 4); and 454 interaction pairs between 254 DEGs (for example, Crot-Ephx2 and Mrpl4-Tars2) were obtained for the SHR-SHRSP shared group (Fig. 5).

Function analysis revealed that 30 significant GO terms (comprising $22 \mathrm{BP}, 5 \mathrm{MF}$ and $3 \mathrm{CC}$ ) were enriched for genes in the SHR-specific group, including GO:0006955 immune response, GO:0030174 regulation of DNA-dependent DNA replication initiation, and GO:0033262 regulation of nuclear cell cycle DNA replication; however, no common genes were involved (Table IV). In addition, 103 significant GO terms (including $64 \mathrm{BP}, 11 \mathrm{MF}$ and $28 \mathrm{CC}$ ) and 9 KEGG pathways were enriched for genes in the SHRSP-specific group, including GO:0030198 extracellular matrix organization (TGFBI), GO:0002062 chondrocyte differentiation (TGFBI), GO:0007623 circadian rhythm (DBP), GO:0001525 angiogenesis (TGFBI) and rno04141:Protein processing in endoplasmic reticulum [heat shock protein family $\mathrm{H}$ (Hsp110) member 1 (HSPH1)] (Table V). Furthermore, 62 significant GO terms (including $32 \mathrm{BP}, 6 \mathrm{MF}$ and $11 \mathrm{CC}$ ) and $13 \mathrm{KEGG}$ pathways were enriched for genes in the SHR-SHRSP shared group, 
Table II. Differentially expressed miRNAs comparing between SHR (or SHRSP) and WKY rats.

A, SHR vs. WKY

\begin{tabular}{|c|c|c|c|}
\hline \multirow[b]{2}{*}{ miRNA } & \multicolumn{3}{|c|}{ SHR vs. WKY } \\
\hline & $\log \mathrm{FC}$ & $\mathrm{P}$-value & FDR \\
\hline rno-miR-31a-3p & 1.66 & $3.99 \mathrm{E}^{-06}$ & $2.87 E^{-03}$ \\
\hline rno-miR-31a-5p & 2.35 & $4.15 E^{-05}$ & $1.49 \mathrm{E}^{-02}$ \\
\hline rno-miR-150-5p & -0.51 & $2.87 E^{-04}$ & $6.88 \mathrm{E}^{-02}$ \\
\hline rno-miR-511-3p & 0.77 & $6.86 E^{-04}$ & $9.87 \mathrm{E}^{-02}$ \\
\hline rno-miR-146b-5p & 0.84 & $5.78 E^{-03}$ & $6.92 \mathrm{E}^{-01}$ \\
\hline rno-miR-146a-5p & -0.56 & $8.54 E^{-03}$ & $7.62 \mathrm{E}^{-01}$ \\
\hline rno-miR-672-5p & -0.74 & $1.67 E^{-02}$ & $7.62 \mathrm{E}^{-01}$ \\
\hline rno-miR-132-3p & 0.76 & $1.70 \mathrm{E}^{-02}$ & $7.62 \mathrm{E}^{-01}$ \\
\hline rno-miR-150-3p & -0.68 & $2.63 \mathrm{E}^{-02}$ & $8.42 \mathrm{E}^{-01}$ \\
\hline rno-miR-3593-3p & -0.56 & $3.44 E^{-02}$ & $8.42 \mathrm{E}^{-01}$ \\
\hline rno-miR-1224 & -0.89 & $3.54 E^{-02}$ & $8.42 \mathrm{E}^{-01}$ \\
\hline
\end{tabular}

B, SHRSP vs. WKY

\begin{tabular}{|c|c|c|c|}
\hline \multirow[b]{2}{*}{ miRNA } & \multicolumn{3}{|c|}{ SHRSP vs. WKY } \\
\hline & $\log \mathrm{FC}$ & P-value & FDR \\
\hline rno-miR-31a-3p & 1.65 & $1.27 \mathrm{E}^{-03}$ & $4.33 \mathrm{E}^{-01}$ \\
\hline rno-miR-126a-5p & -0.58 & $1.91 E^{-03}$ & $4.33 \mathrm{E}^{-01}$ \\
\hline rno-miR-196a-5p & 2.11 & $2.52 \mathrm{E}^{-03}$ & $4.33 \mathrm{E}^{-01}$ \\
\hline rno-miR-146a-5p & -0.85 & $2.98 \mathrm{E}^{-03}$ & $4.33 \mathrm{E}^{-01}$ \\
\hline rno-miR-150-5p & -0.51 & $3.05 E^{-03}$ & $4.33 \mathrm{E}^{-01}$ \\
\hline rno-miR-31a-5p & 2.12 & $3.61 E^{-03}$ & $4.33 \mathrm{E}^{-01}$ \\
\hline rno-miR-126a-3p & -0.53 & $1.57 \mathbf{E}^{-02}$ & $1.00 \mathrm{E}^{-01}$ \\
\hline rno-miR-511-3p & 0.73 & $2.10 \mathrm{E}^{-02}$ & $1.00 \mathrm{E}^{-01}$ \\
\hline rno-miR-21-5p & 0.70 & $2.39 \mathrm{E}^{-02}$ & $1.00 \mathrm{E}^{-01}$ \\
\hline rno-miR-1224 & -1.43 & $2.57 \mathrm{E}^{-02}$ & $1.00 \mathrm{E}^{-01}$ \\
\hline rno-miR-672-5p & -1.01 & $2.60 \mathrm{E}^{-02}$ & $1.00 \mathrm{E}^{-01}$ \\
\hline rno-miR-196b-5p & 1.98 & $2.76 \mathrm{E}^{-02}$ & $1.00 \mathrm{E}^{-01}$ \\
\hline rno-miR-483-3p & -0.66 & $4.14 \mathrm{E}^{-02}$ & $1.00 \mathrm{E}^{-01}$ \\
\hline
\end{tabular}

Values in bold indicate $\mathrm{P}<0.05$ or $\mathrm{FDR}<0.05$. FDR, false discovery rate; FC, fold change; SHR, spontaneously hypertensive rats; SHRSP, stroke-prone spontaneously hypertensive rats.

including GO:0006954 inflammatory response [epoxide hydrolase 2 (EPHX2)], GO:0055114 oxidation-reduction process (ALDH5A1), GO:0032355 response to estradiol (ENDOG), GO:0006631 fatty acid metabolic process (CROT), GO:0007417 central nervous system development (ALDH5A1), GO:0004829 threonine-tRNA ligase activity (TARS2) and rno00650:Butanoate metabolism (ALDH5A1) (Table VI).

miRNA-mRNA regulatory network. After integrating the target genes of DEMs with the common DEGs (consistent expression trend) in two datasets, 97 negative interaction pairs between 17 miRNAs and 18 DEGs were identified, including SHRSP-specific rno-miR-126a-5p-Dbp/Torlb, rno-miR-196a-5p/rno-miR-196b-5p/rno-miR-21-5p-Tgfbi, and SHR-SHRSP shared rno-miR-672-5p-Zfp597 and rno-miR-31a-5p-Crot/Mrpl4, which were used for constructing the miRNA-mRNA regulatory network (Fig. 6).

Prediction of potential therapeutic agents. After uploading the upregulated and downregulated DEGs to the CMAP database, a serial of small-molecule drugs that may exert therapeutic potential for SHR were predicted, including botulin, Gly-His-Lys, benzathine benzylpenicillin, Prestwick-1103, PF-00539745-00, quinostatin, 5279552 and podophyllotoxin (Table VII).

\section{Discussion}

By integrating the results of the miRNA regulatory network, PPI network and function enrichment, the present study has demonstrated that changes in the expression of Dbp, Crot and Mrp14 (all $\mathrm{P}<0.01$, especially the latter one with FDR $<0.05$ in all datasets) may possibly be important genetic changes associated with SHRSP: Upregulated Dbp is associated with circadian rhythm and regulated by rno-miR-126a-5p, whereas downregulated Crot may participate in fatty acid metabolic processes or the inflammatory response by interacting with EPHX2. Downregulated Mrpl4 may exert roles by interacting with threonine-tRNA ligase TARS2. Expression of Crot and Mrpl4 may both be modulated by rno-miR-31a.

Accumulating evidence has demonstrated abnormal BP circadian rhythm is associated with the development of hypertension (24) and stroke (25). Normal circadian BP is in a 'dipper' pattern, with a decline in nocturnal BP of $10-20 \%$ compared with the day time (24). Patients with non-dipper (i.e., a lack of nocturnal BP fall) patterns of circadian BP rhythm are found to have a 4.222-fold increased risk for the development of hypertension ( $\mathrm{P}=0.011)$ (26). Furthermore, non-dipper (risk ratio=1.42) or reverse-dipper (odds ratio $=2.492$ ) patterns of BP were also shown to be stronger risk factors for the occurrence of stroke in patients with essential hypertension (i.e., high BP that lacks a known secondary cause) $(25,27,28)$. Therefore, genes that regulate the circadian rhythm may be potentially associated with the pathogenesis of hypertension and stroke. This hypothesis has been validated in a previously published study (29). For example, Leu et al (30) identified genetic polymorphisms in five circadian clock genes [neuronal PAS domain protein 2 (NPAS2), rs3888170; period circadian regulator 2 (PER2), rs6431590; retinoic acid receptor-related orphan receptor $\beta \beta$ (ROR $\beta \beta)$, rs1410225; brain and muscle ARNT-like 1 (BMAL1), rs3816358; and ROR $\alpha$, rs10519096], and these were significantly associated with the non-dipper phenotype in 372 young hypertensive patients. The study of Corella et al (31) revealed that CLOCK-rs4580704 single nucleotide polymorphism (SNP) was associated with an increased risk of stroke in type-2 diabetic subjects, with CC-carriers having a higher risk (31). Kurbatova et al (32) observed further that the transcript expression levels of 
Table III. Differentially expressed genes between SHR (or SHRSP) and WKY.

\begin{tabular}{|c|c|c|c|c|c|c|c|}
\hline & \multirow[b]{2}{*}{ Gene } & \multicolumn{3}{|c|}{ GSE31457-GSE41452-GSE41453 } & \multicolumn{3}{|c|}{ GSE53363 } \\
\hline & & $\log \mathrm{FC}$ & P-value & FDR & $\log \mathrm{FC}$ & P-value & FDR \\
\hline \multirow[t]{2}{*}{ SHR-specific } & Ch25h & 0.51 & $4.25 \mathrm{E}^{-03}$ & $3.40 \mathrm{E}^{-01}$ & 0.62 & $6.53 E^{-03}$ & $3.82 \mathrm{E}^{-01}$ \\
\hline & Sec16b & 0.67 & $2.61 \mathrm{E}^{-02}$ & $9.16 \mathrm{E}^{-01}$ & 0.50 & $5.58 \mathrm{E}^{-03}$ & $3.71 \mathrm{E}^{-01}$ \\
\hline \multirow[t]{8}{*}{ SHRSP-specific } & RGD1310414 & 0.57 & $1.44 E^{-06}$ & $8.96 \mathrm{E}^{-04}$ & 0.53 & $2.70 E^{-03}$ & $1.64 \mathrm{E}^{-01}$ \\
\hline & Nr1d2 & 0.58 & $6.35 E^{-04}$ & $1.10 \mathrm{E}^{-01}$ & 0.54 & $2.69 \mathrm{E}^{-03}$ & $1.64 \mathrm{E}^{-01}$ \\
\hline & Dbp & 0.97 & $1.15 E^{-03}$ & $1.63 \mathrm{E}^{-01}$ & 0.87 & $4.76 \mathrm{E}^{-03}$ & $2.05 \mathrm{E}^{-01}$ \\
\hline & LOC686388 & -0.53 & $1.41 \mathrm{E}^{-03}$ & $1.81 \mathrm{E}^{-01}$ & -0.60 & $6.61 E^{-04}$ & $8.71 \mathrm{E}^{-02}$ \\
\hline & $\mathrm{Mb}$ & -0.53 & $3.18 \mathrm{E}^{-03}$ & $3.05 \mathrm{E}^{-01}$ & 0.54 & $4.04 E^{-04}$ & $7.10 \mathrm{E}^{-02}$ \\
\hline & Pigzl1 & 1.23 & $4.50 \mathrm{E}^{-02}$ & $1.00 \mathrm{E}^{-01}$ & 0.63 & $3.13 E^{-02}$ & $4.07 \mathrm{E}^{-01}$ \\
\hline & Tgfbi & -0.57 & $4.66 \mathrm{E}^{-02}$ & $1.00 \mathrm{E}^{-01}$ & -0.62 & $2.09 \mathrm{E}^{-02}$ & $3.59 \mathrm{E}^{-01}$ \\
\hline & Tef & 0.822 & $4.84 E^{-02}$ & $1.00 \mathrm{E}^{-01}$ & 0.74 & $1.53 E^{-02}$ & $3.20 \mathrm{E}^{-01}$ \\
\hline \multirow[t]{15}{*}{ SHR-SHRSP (SHRSP) } & Endog & -1.52 & $5.13 E^{-09}$ & $7.06 \mathrm{E}^{-06}$ & -0.94 & $9.03 E^{-06}$ & $6.20 \mathrm{E}^{-03}$ \\
\hline & Tor1b & 1.29 & $7.91 \mathrm{E}^{-09}$ & $1.02 \mathrm{E}^{-05}$ & 1.37 & $1.69 E^{-08}$ & $7.75 E^{-05}$ \\
\hline & Chmp1b & -1.08 & $1.16 \mathrm{E}^{-08}$ & $1.40 \mathrm{E}^{-05}$ & -0.70 & $8.21 E^{-04}$ & $9.27 \mathrm{E}^{-02}$ \\
\hline & Riok1 & 0.96 & $2.01 E^{-06}$ & $1.21 \mathrm{E}^{-03}$ & 0.66 & $4.15 E^{-04}$ & $7.14 \mathrm{E}^{-02}$ \\
\hline & Fkbp5 & 1.25 & $1.15 \mathrm{E}^{-05}$ & $5.05 \mathrm{E}^{-03}$ & 1.76 & $7.83 E^{-06}$ & $5.70 E^{-03}$ \\
\hline & Mrpl4 & -0.74 & $4.99 \mathrm{E}^{-05}$ & $1.58 \mathrm{E}^{-02}$ & -0.87 & $5.28 \mathrm{E}^{-06}$ & $5.00 E^{-03}$ \\
\hline & RGD1562351 & -0.89 & $3.21 E^{-04}$ & $6.80 \mathrm{E}^{-02}$ & -0.50 & $7.14 \mathrm{E}^{-03}$ & $2.42 \mathrm{E}^{-01}$ \\
\hline & Tars2 & -0.66 & $5.01 E^{-04}$ & $9.04 \mathrm{E}^{-02}$ & -0.93 & $4.27 E^{-07}$ & $7.32 \mathrm{E}^{-04}$ \\
\hline & Crot & -0.77 & $1.27 \mathrm{E}^{-03}$ & $1.74 \mathrm{E}^{-01}$ & -0.52 & $9.78 \mathrm{E}^{-03}$ & $2.83 \mathrm{E}^{-01}$ \\
\hline & Zfp597 & 1.37 & $2.35 \mathrm{E}^{-03}$ & $2.52 \mathrm{E}^{-01}$ & 1.00 & $2.64 E^{-05}$ & $1.32 E^{-02}$ \\
\hline & Ms4a11 & 0.76 & $4.37 \mathrm{E}^{-03}$ & $3.72 \mathrm{E}^{-01}$ & 1.09 & $7.76 \mathrm{E}^{-03}$ & $2.52 \mathrm{E}^{-01}$ \\
\hline & Aldh5a1 & -0.59 & $5.85 \mathrm{E}^{-03}$ & $4.45 \mathrm{E}^{-01}$ & -0.51 & $2.75 E^{-03}$ & $1.66 \mathrm{E}^{-01}$ \\
\hline & Retsat & -1.07 & $1.10 \mathrm{E}^{-02}$ & $6.08 \mathrm{E}^{-01}$ & -0.66 & $4.09 \mathrm{E}^{-02}$ & $4.45 \mathrm{E}^{-01}$ \\
\hline & Pxmp4 & -0.68 & $1.42 \mathrm{E}^{-02}$ & $7.07 \mathrm{E}^{-01}$ & 0.93 & $1.02 E^{-05}$ & $6.67 E^{-03}$ \\
\hline & Tmem14a & 0.67 & $1.75 E^{-02}$ & $7.93 \mathrm{E}^{-01}$ & 0.80 & $6.04 E^{-06}$ & $5.00 \mathrm{E}^{-03}$ \\
\hline \multirow[t]{15}{*}{ SHR-SHRSP (SHR) } & Endog & -1.54 & $1.30 \mathrm{E}^{-09}$ & $1.94 E^{-06}$ & -0.71 & $4.88 \mathrm{E}^{-04}$ & $1.01 \mathrm{E}^{-01}$ \\
\hline & Tor1b & 1.27 & $3.43 E^{-08}$ & $2.55 \mathrm{E}^{-05}$ & 1.04 & $1.01 E^{-04}$ & $4.38 \mathrm{E}^{-02}$ \\
\hline & Chmp1b & -1.09 & $7.64 \mathrm{E}^{-09}$ & $7.37 \mathbf{E}^{-06}$ & -0.88 & $4.82 E^{-05}$ & $2.81 \mathrm{E}^{-02}$ \\
\hline & Riok1 & 0.98 & $1.38 \mathrm{E}^{-07}$ & $6.17 E^{-03}$ & 0.56 & $3.63 \mathrm{E}^{-03}$ & $3.00 \mathrm{E}^{-01}$ \\
\hline & Fkbp5 & 1.20 & $5.53 \mathrm{E}^{-06}$ & $2.32 \mathrm{E}^{-03}$ & 1.22 & $9.36 \mathrm{E}^{-04}$ & $1.67 \mathrm{E}^{-01}$ \\
\hline & Mrpl4 & -0.68 & $1.82 E^{-05}$ & $6.17 E^{-03}$ & -0.90 & $1.93 \mathrm{E}^{-06}$ & $4.40 \mathrm{E}^{-03}$ \\
\hline & RGD1562351 & -0.81 & $1.163 \mathrm{E}^{-03}$ & $1.45 \mathrm{E}^{-01}$ & -0.60 & $8.74 E^{-04}$ & $1.60 \mathrm{E}^{-01}$ \\
\hline & Tars2 & -0.61 & $8.61 E^{-04}$ & $1.18 \mathrm{E}^{-01}$ & -0.721 & $1.21 E^{-04}$ & $4.54 \mathrm{E}^{-02}$ \\
\hline & Crot & -0.61 & $1.26 \mathrm{E}^{-02}$ & $6.10 \mathrm{E}^{-01}$ & -0.53 & $4.67 E^{-03}$ & $0.3 .48 \mathrm{E}^{-01}$ \\
\hline & Zfp597 & 1.35 & $5.63 E^{-03}$ & $3.92 \mathrm{E}^{-01}$ & 0.94 & $6.49 E^{-05}$ & $3.07 E^{-02}$ \\
\hline & Ms4a11 & 0.80 & $1.34 E^{-02}$ & $6.33 \mathrm{E}^{-01}$ & 0.71 & $2.24 \mathrm{E}^{-02}$ & $5.98 \mathrm{E}^{-01}$ \\
\hline & Aldh5a1 & -0.55 & $8.58 E^{-03}$ & $5.12 \mathrm{E}^{-01}$ & -0.58 & $3.00 E^{-04}$ & $7.34 \mathrm{E}^{-02}$ \\
\hline & Retsat & -0.96 & $2.42 \mathrm{E}^{-02}$ & $8.81 \mathrm{E}^{-01}$ & -0.61 & $3.19 E^{-02}$ & $6.45 \mathrm{E}^{-01}$ \\
\hline & Pxmp4 & -0.79 & $9.60 \mathrm{E}^{-03}$ & $5.41 \mathrm{E}^{-01}$ & 0.77 & $2.78 E^{-04}$ & $6.95 \mathrm{E}^{-02}$ \\
\hline & Tmem14a & 0.81 & $4.98 \mathrm{E}^{-03}$ & $3.72 \mathrm{E}^{-01}$ & 0.93 & $1.14 E^{-03}$ & $1.84 \mathrm{E}^{-01}$ \\
\hline
\end{tabular}

Values in bold indicate $\mathrm{P}<0.05$ or FDR $<0.05$. FDR, false discovery rate; FC, fold change; SHR, spontaneously hypertensive rats; SHRSP, stroke-prone SHR rats.

CLOCK, BMAL1 and PER were differentially regulated in hypertension patients with various genotypes (32). In the SHR rat, small interfering RNA-mediated knockdown of Perl was shown to significantly reduce BP $(33,34)$. Bmal1-deficient female mice were also observed to exhibit a significantly smaller infarct core volume compared with female $\mathrm{Bmall}^{+/+}$mice at 14 days after the induction of photothrombosis (35). In line with these studies, the present study also revealed that Dbp, a clock-controlled transcription factor, was significantly upregulated in all analyzed tissues 
A

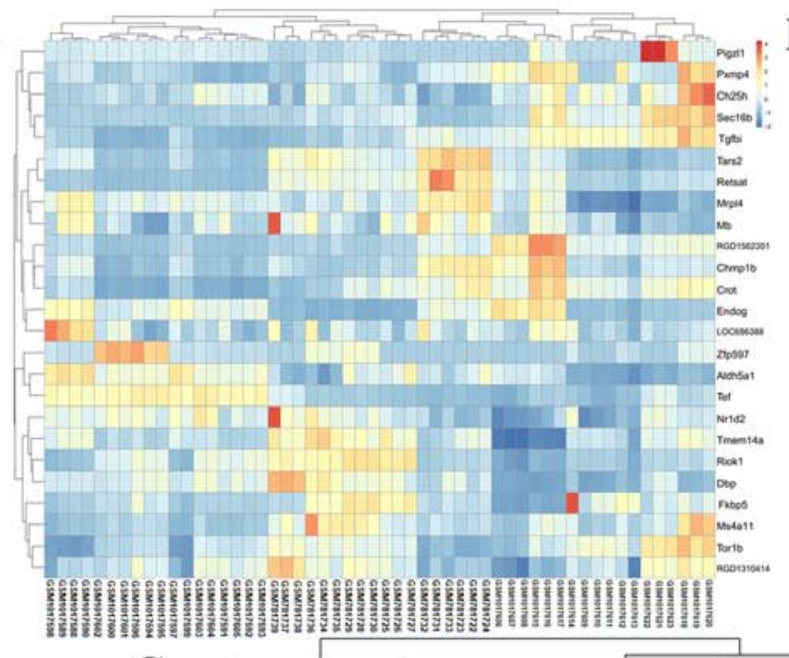

B

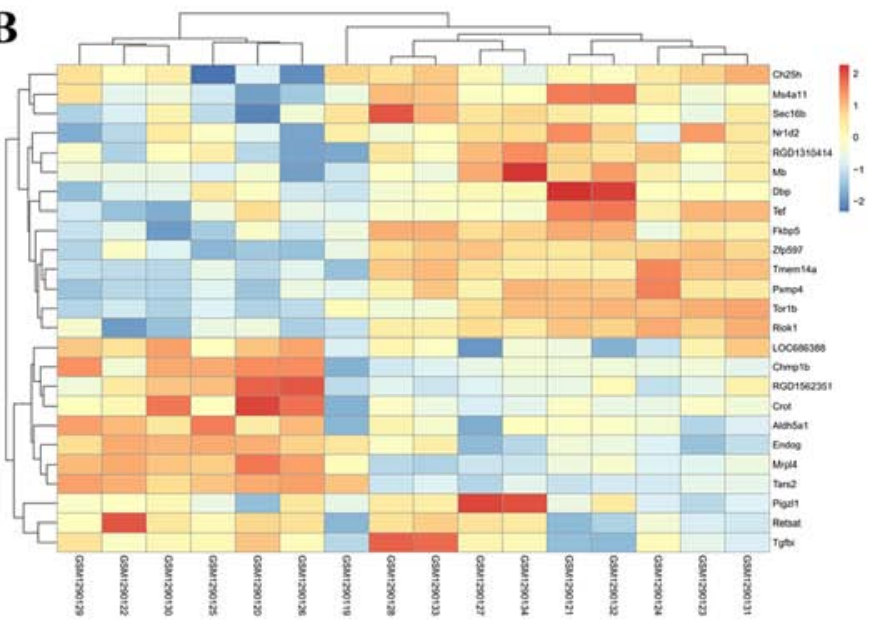

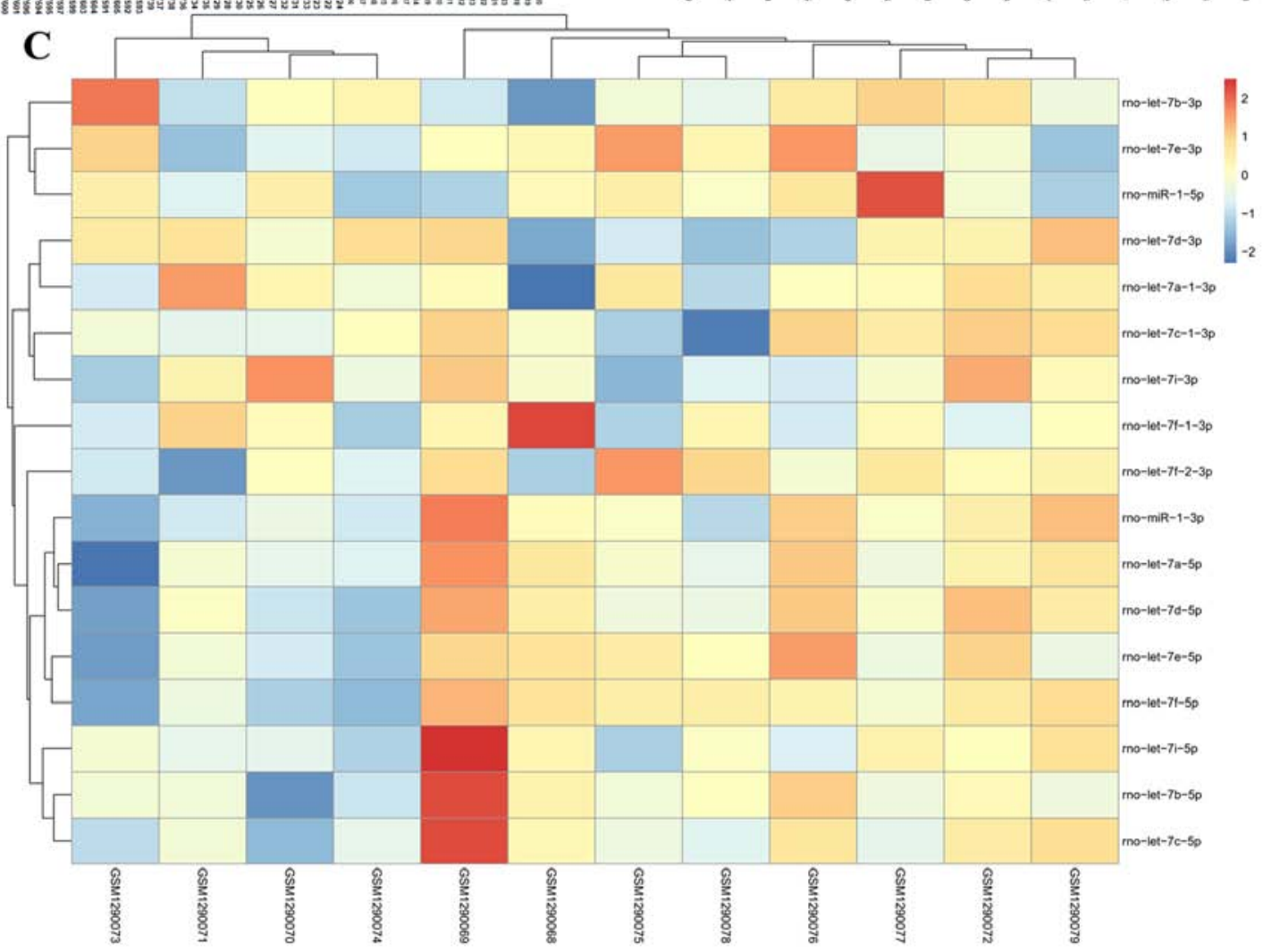

Figure 2. Hierarchical clustering and heat-map analysis of differentially expressed (A and B) genes and (C) miRNAs. (A) 3GSE31457-GSE41452-GSE41453; (B) GSE53361; (C) GSE53361. The deep-red color denotes high expression; dark blue indicates low expression.

of SHRSP rats compared with WKY rats. These results were dissimilar to a previous study performed with SHR rats, in which the expression of Dbp occurred differentially in heart (significant expression) and aortas (no expression), although it was also relatively higher compared with WKY rats (36). These findings further verified that Dbp may be a specific target for treatment of SHRSP, and that downregulation of Dbp may represent a potential therapeutic approach.

Relative to direct knockout of the specific target gene, the introduction of endogenous non-coding miRNAs that negatively regulate this gene may be safer. Therefore, miRNAs that could regulate the expression of Dbp were also investigated in our study. Our results predicted that miR-126 could bind with Dbp at the 3'-untranslated region, and thereby overexpression of miR-126 may represent a potential therapeutic approach for
SHRSP via the suppression of Dbp expression. Other studies have also reported on the association of miR-126 with the development of stroke. Jin and Xing $(37,38)$ reported that the plasma miR-126 expression level was lower in patients with acute ischemic stroke compared with those of controls, and its expression was negatively correlated with National Institutes of Health Stroke Scale (NIHSS) scores. Overexpression of miR-126 in the stem cells attenuated the infarct volume, improved functional recovery, enhanced neurogenesis, and inhibited neuroinflammation $(39,40)$. These studies indirectly indicated that a negative correlation existed between miR-126 and Dbp in stroke. However, direct evidence that may have been used to investigate the regulatory relationship between them was lacking, and the present study may provide a novel mechanism for explaining the pathogenesis of SHRSP. 


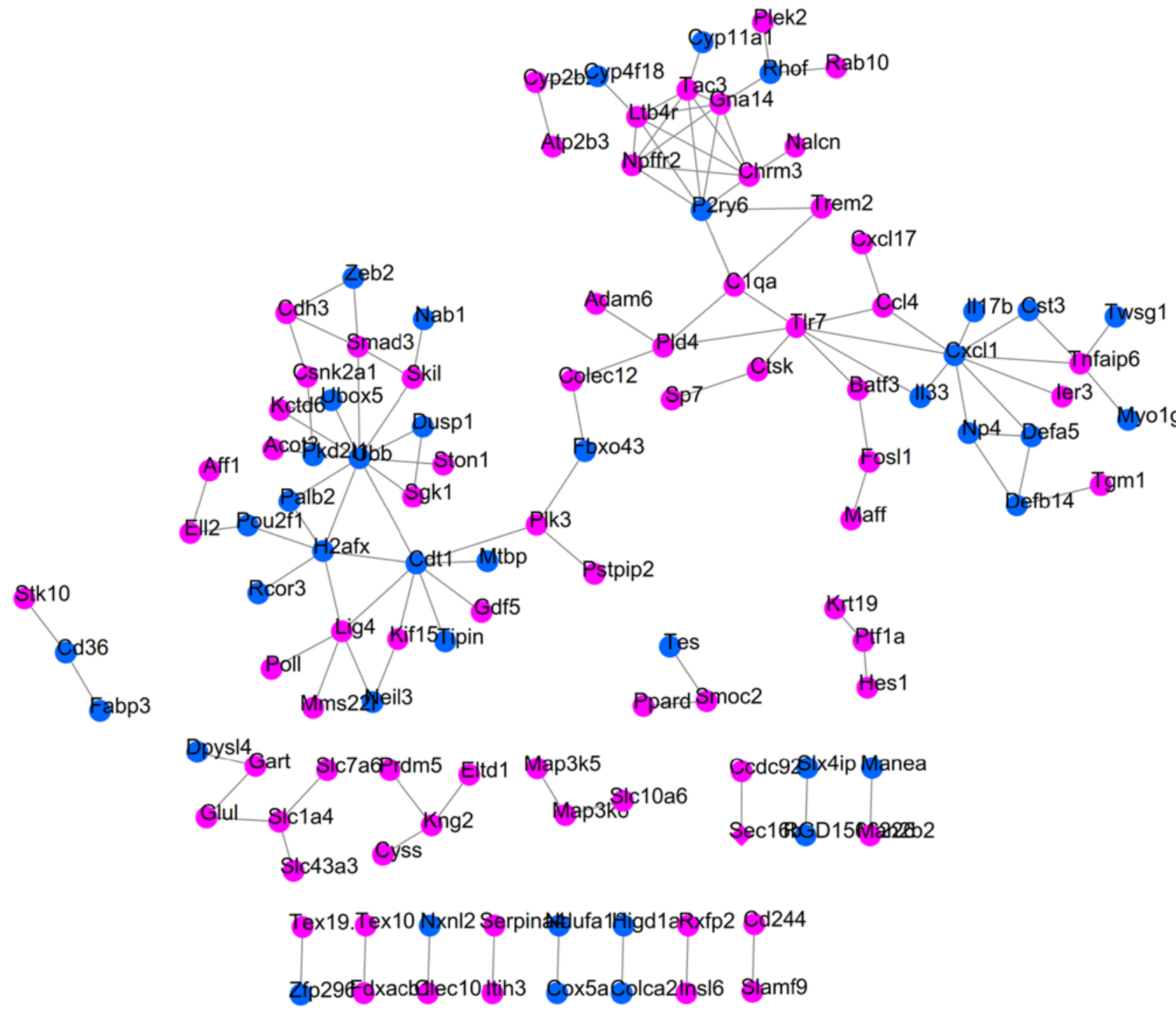

Figure 3. Protein-protein interaction network for SHR-specific genes. Dark pink represents upregulated genes; blue illustrates the downregulated genes. SHR, spontaneously hypertensive rats.

The CROT gene encodes a member of the carnitine/choline acetyltransferase family that converts 4,8-dimethylnonanoyl-CoA into its corresponding carnitine ester, and facilitates the transport of medium- and long-chain acyl-CoA molecules out of the peroxisome to the cytosol and mitochondria as a feature of the fatty acid oxidation process. Downregulation of CROT may contribute to impaired fatty acid oxidation and thus promote fat accumulation, leading to the development of obesity (41-43). Obesity is considered to be important risk factors for hypertension (44) and stroke (45). Thus, CROT may also be expressed at a lower level in SHR and SHRSP rats, a finding which was, for the first time to the best of our knowledge, confirmed in our study. Furthermore, it has also been reported that obesity may induce hypertension and stroke according to a pro-inflammatory mechanism $(46,47)$. Therefore, CROT was also hypothesized to inhibit inflammation. Although some experimental evidence has been provided in support of this hypothesis (41), our hypothesis was that CROT may indirectly exert an anti-inflammatory effect by interacting with EPHX2, a member of epoxide hydrolase family, since it was enriched in the inflammatory response process in our study. Furthermore, the study of Ulu et al (48) demonstrated that an epoxide hydrolase inhibitor enhanced the anti-hypertensive and anti-inflammatory effects of omega-3 polyunsaturated fatty acids, providing further indirect support for our hypothesis. Moreover, few previous studies have been concerned with miRNAs that regulate the expression of CROT, other than miR-33 (41). The present study has, for the first time, revealed that miR-31 may also regulate CROT, and this process may be involved in the development of SHR and SHRSP. Although no direct evidence has been provided to prove that miR-31 is important for stroke and hypertension, its roles in mediating the production of inflammatory cytokines (49) may reveal the possible interaction between miR-31 and CROT.

In addition, the present study has identified that miR-31 regulates Mrpl4, and therefore Mrpl4 may also be associated with inflammation in SHR and SHRSP. Although studies on Mrpl4 are relatively rare, its potential roles in inflammation have been investigated previously. For example, MRPL4 was reported to be a downregulated downstream target of 


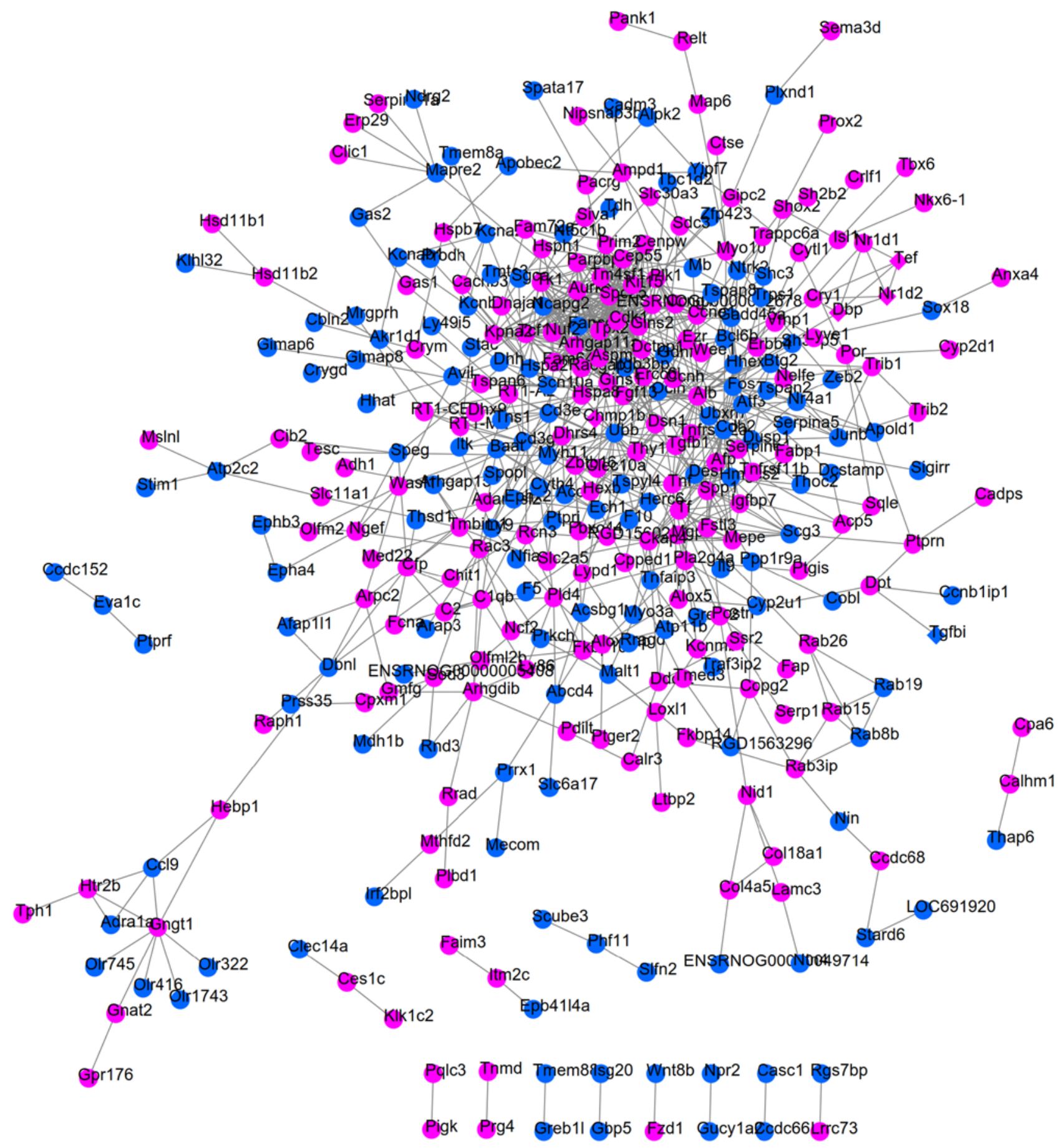

Figure 4. Protein-protein interaction network for SHRSP-specific genes. Dark pink represents upregulated genes; blue illustrates the downregulated genes. SHRSP, stroke-prone SPR rats.

hypoxia-inducible factor-1 $\alpha(\mathrm{HIF}-1 \alpha)(50)$. Accumulation of HIF-1 $\alpha$ was observed in neurons of 9-month-old SHR and SHRSP rats (51). Deletion of HIF-1 $\alpha$ was shown to significantly reduce vascular high pressure and vascular inflammation, attenuate atherosclerosis (52), and improve neuronal survival and sensorimotor function in ischemic stroke (53). Furthermore, our prediction was also that Mrpl4 could interact with TARS2. It was previously reported that secreted TARS stimulated endothelial cell migration and angiogenesis (54), which was beneficial for neurogenesis and functional recovery in patients with stroke (55).
Accordingly, the present study has suggested miR-31 may be involved in SHRSP by regulating MRPL4 to mediate inflammation and angiogenesis inhibition.

Furthermore, the analysis of small-molecule drugs in the present study revealed that botulin, Gly-His-Lys and podophyllotoxin may potentially be agents for treatment of SHR and SHRSP. Although no evidence exists based on the study of their therapeutic effects on SHR and SHRSP, their anti-inflammatory activities may indirectly reveal their therapeutic potential. For example, botulinum toxin type A treatment was demonstrated to reduce persistent 


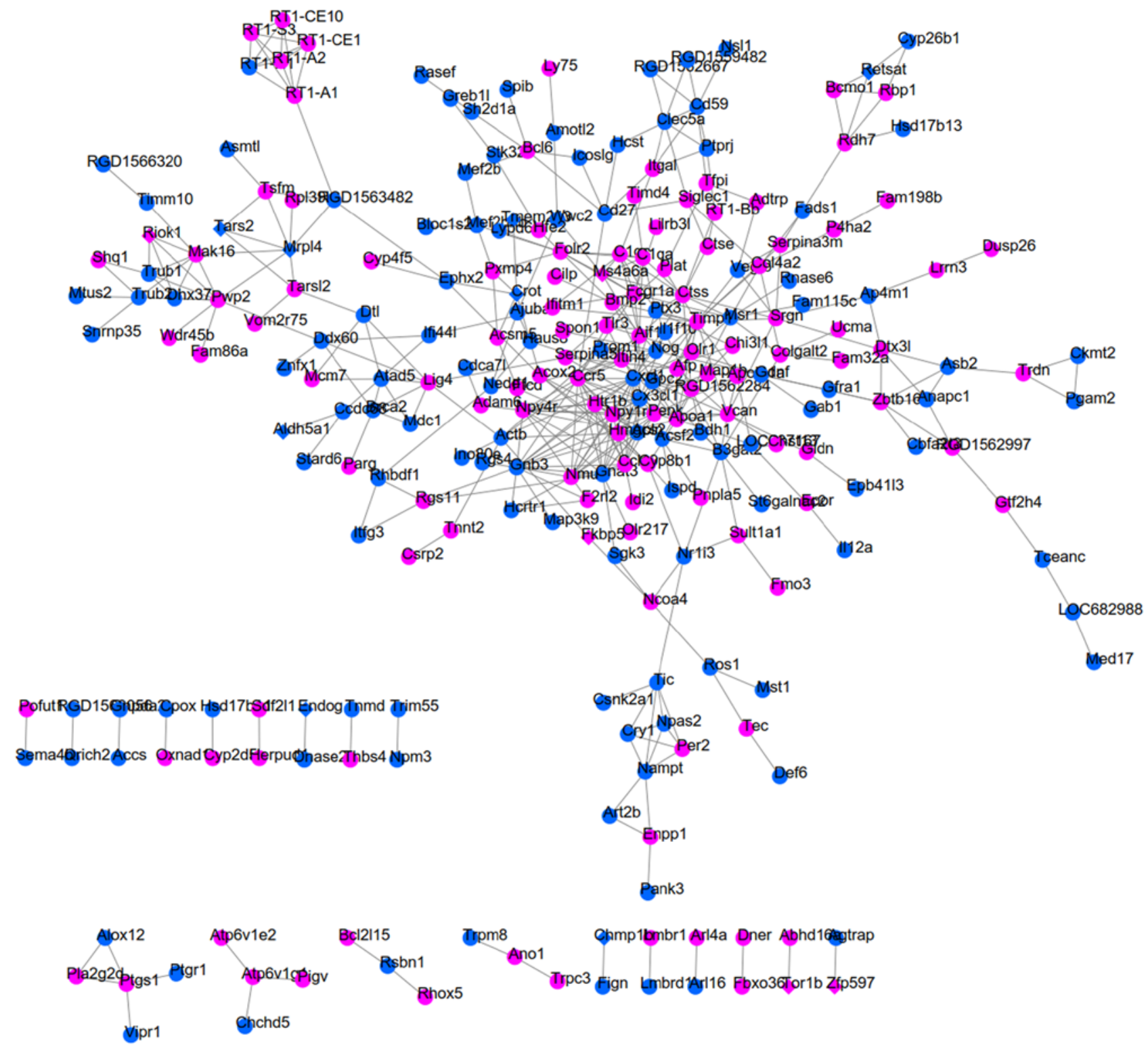

Figure 5. Protein-protein interaction network for SHR-SHRSP shared genes. Dark pink represents upregulated genes; blue illustrates the downregulated genes. SHR, spontaneously hypertensive rats; SHRSP, stroke-prone spontaneously hypertensive rats.
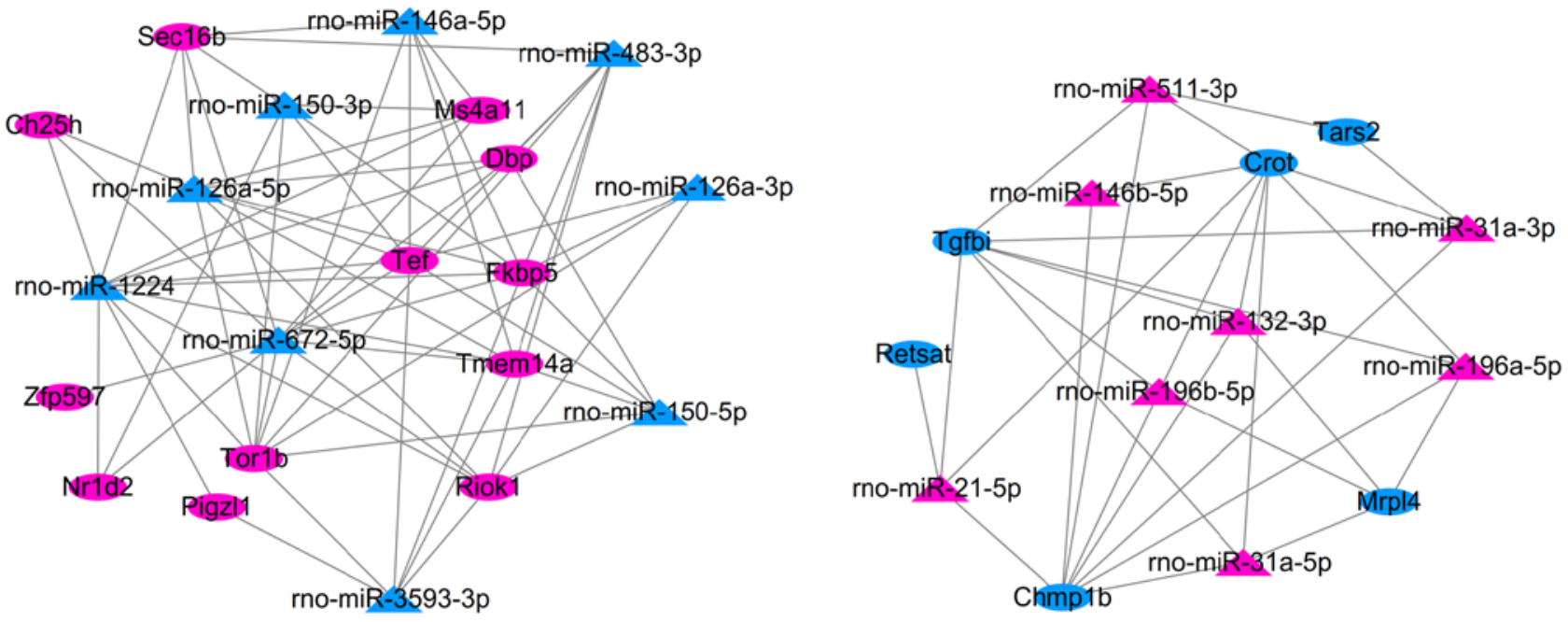

Figure 6. The miRNA-mRNA regulatory network. Dark pink represents upregulated genes; blue illustrates the downregulated genes; triangles denote miRNAs, whereas ovals indicate mRNAs. 
Table IV. Function enrichment analysis for genes of the SHR-specific group of the PPI network.

\begin{tabular}{|c|c|c|c|}
\hline Category & Term & P-value & Genes \\
\hline GO BP & GO:0008584 male gonad development & $2.69 \mathrm{E}^{-04}$ & $\begin{array}{l}\text { TEX19.1, ADAM6, CYP11A1, RXFP2, CST3, } \\
\text { UBB, INSL6 }\end{array}$ \\
\hline GO BP & $\begin{array}{l}\text { GO:0050728 negative regulation of } \\
\text { inflammatory response }\end{array}$ & $1.76 \mathrm{E}^{-03}$ & CXCL17, IER3, TNFAIP6, PPARD, SMAD3 \\
\hline GO BP & $\begin{array}{l}\text { GO:0043066 negative regulation of apoptotic } \\
\text { process }\end{array}$ & $4.11 \mathrm{E}^{-03}$ & $\begin{array}{l}\text { IER3, PPARD, SGK1, PLK3, DUSP1, RXFP2, SMAD3, } \\
\text { PALB2, INSL6, HIGD1A }\end{array}$ \\
\hline GO BP & GO:0031640 killing of cells of other organism & $1.80 \mathrm{E}^{-02}$ & DEFA5, NP4 \\
\hline GO BP & $\begin{array}{l}\text { GO:0030513 positive regulation of BMP } \\
\text { signaling pathway }\end{array}$ & $2.00 \mathrm{E}^{-02}$ & HES1, TWSG1, GDF5 \\
\hline GO BP & GO:0006955 immune response & $2.30 \mathrm{E}^{-02}$ & CXCL1, CD244, CD36, SMAD3, COLEC12, CCL4 \\
\hline GO BP & GO:0001562 response to protozoan & $2.40 \mathrm{E}^{-02}$ & IER3, CYSS \\
\hline GO BP & $\begin{array}{l}\text { GO:0030174 regulation of DNA-dependent } \\
\text { DNA replication initiation }\end{array}$ & $2.40 \mathrm{E}^{-02}$ & TEX10, CDT1 \\
\hline GO BP & $\begin{array}{l}\text { GO:0014070 response to organic cyclic } \\
\text { compound }\end{array}$ & $2.47 \mathrm{E}^{-02}$ & HES1, CYP2B2, CYP11A1, CYSS, CST3, FOSL1 \\
\hline GO BP & GO:0001701 in utero embryonic development & $2.76 \mathrm{E}^{-02}$ & HES1, MAFF, SMAD3, LIG4, PALB2, FOSL1 \\
\hline GO BP & GO:0007431 salivary gland development & $3.00 \mathrm{E}^{-02}$ & CYSS, CST3 \\
\hline GO BP & $\begin{array}{l}\text { GO:0033262 regulation of nuclear cell cycle } \\
\text { DNA replication }\end{array}$ & $3.00 \mathrm{E}^{-02}$ & TIPIN, CDT1 \\
\hline GO BP & GO:0010332 response to gamma radiation & $3.10 \mathrm{E}^{-02}$ & CXCL1, CYP11A1, LIG4 \\
\hline GO BP & GO:0046677 response to antibiotic & $3.28 \mathrm{E}^{-02}$ & CYP11A1, CYSS, SKIL \\
\hline GO BP & GO:0006952 defense response & $3.41 \mathrm{E}^{-02}$ & CXCL1, NP4, CST3 \\
\hline GO BP & GO:0006954 inflammatory response & $3.43 \mathrm{E}^{-02}$ & CXCL1, IL17B, KNG2, LTB4R, CCL4, TLR7 \\
\hline GO BP & $\begin{array}{l}\text { GO:0032755 positive regulation of } \\
\text { interleukin- } 6 \text { production }\end{array}$ & $3.67 \mathrm{E}^{-02}$ & CD36, IL33, TLR7 \\
\hline GO BP & GO:0042493 response to drug & $4.10 \mathrm{E}^{-02}$ & $\begin{array}{l}\text { CD36, CYP11A1, CYSS, CST3, FABP3, NDUFA10, } \\
\text { CDH3, FOSL1 }\end{array}$ \\
\hline GO BP & GO:0000076 DNA replication checkpoint & $4.16 \mathrm{E}^{-02}$ & TIPIN, CDT1 \\
\hline GO BP & GO:0044539 long-chain fatty acid import & $4.16 \mathrm{E}^{-02}$ & CD36, FABP3 \\
\hline GO BP & GO:0001756 somitogenesis & $4.39 \mathrm{E}^{-02}$ & SMAD3, ZEB2, PALB2 \\
\hline GO BP & $\begin{array}{l}\text { GO:0071356 cellular response to tumor } \\
\text { necrosis factor }\end{array}$ & $4.68 \mathrm{E}^{-02}$ & HES1, MAP3K5, CYP11A1, CCL4 \\
\hline \multirow[t]{5}{*}{ GO MF } & GO:0003677 DNA binding & $6.91 \mathrm{E}^{-04}$ & $\begin{array}{l}\text { BATF3, POLL, RCOR3, PTF1A, TIPIN, SMAD3, } \\
\text { ZEB2, LIG4, CDT1, HES1, POU2F1, H2AFX, SP7, } \\
\text { SKIL, PALB2, FOSL1 }\end{array}$ \\
\hline & GO:0070538 oleic acid binding & $1.63 \mathrm{E}^{-02}$ & CD36, FABP3 \\
\hline & $\begin{array}{l}\text { GO:0004869 cysteine-type endopeptidase } \\
\text { inhibitor activity }\end{array}$ & $2.31 \mathrm{E}^{-02}$ & KNG2, CYSS, CST3 \\
\hline & $\begin{array}{l}\text { GO:0001078 transcriptional repressor activity, } \\
\text { RNA polymerase II core promoter proximal } \\
\text { region sequence-specific binding }\end{array}$ & $2.69 \mathrm{E}^{-02}$ & BATF3, HES1, PRDM5, SKIL \\
\hline & GO:0004559 alpha-mannosidase activity & $4.29 \mathrm{E}^{-02}$ & MAN2B2, MANEA \\
\hline \multirow[t]{3}{*}{$\mathrm{GO} \mathrm{CC}$} & GO:0005615 extracellular space & $7.23 \mathrm{E}^{-04}$ & $\begin{array}{l}\text { CXCL1, TWSG1, KNG2, DEFB14, GDF5, CST3, } \\
\text { IL33, CCL4, CXCL17, TNFAIP6, CTSK, CD36, } \\
\text { IL17B, DEFA5, SERPINA4, NP4, CYSS, FABP3, UBB }\end{array}$ \\
\hline & $\begin{array}{l}\text { GO:0043231 intracellular membrane-bounded } \\
\text { organelle }\end{array}$ & $7.83 \mathrm{E}^{-03}$ & $\begin{array}{l}\text { SEC16B, CYP2B2, GLUL, ATP2B3, KNG2, CD36, } \\
\text { POU2F1, TIPIN, TREM2, FOSL1, PKD2L1 }\end{array}$ \\
\hline & GO:0000785 chromatin & $3.77 \mathrm{E}^{-02}$ & HES1, PLK3, MTBP, H2AFX \\
\hline
\end{tabular}

BP, biological process; MF, molecular function; CC, cellular component; GO, Gene ontology; KEGG, Kyoto encyclopedia of genes and genomes; PPI, protein-protein interaction; SHR, spontaneously hypertensive rats. 
Table V. Function enrichment analysis for the genes of the SHRSP group of the PPI network.

\begin{tabular}{|c|c|c|c|}
\hline Category & Term & P-value & Genes \\
\hline GO BP & GO:0032570 response to progesterone & $1.00 \mathrm{E}^{-05}$ & $\begin{array}{l}\text { CCNE1, FOS, PTGER2, NCF2, ERBB4, ADH1, HSPA8, } \\
\text { JUNB, TGFB1 }\end{array}$ \\
\hline GO BP & $\begin{array}{l}\text { GO:0010033 response to organic } \\
\text { substance }\end{array}$ & $1.69 \mathrm{E}^{-05}$ & $\begin{array}{l}\text { TNF, CYP2D1, MGP, TGFB1, AMPD1, AFP, C1QB, } \\
\text { PLA2G4A, BTG2, DUSP1, ALB, SQLE, SPP1 }\end{array}$ \\
\hline GO BP & GO:0007067 mitotic nuclear division & $7.62 \mathrm{E}^{-05}$ & $\begin{array}{l}\text { ITGB3BP, SPC25, CDK1, PLK1, NUF2, CENPW, } \\
\text { MAPRE2, FABP1, CEP55, CCNG1, WEE1 }\end{array}$ \\
\hline GO BP & $\begin{array}{l}\text { GO:0000122 negative regulation of } \\
\text { transcription from RNA polymerase II } \\
\text { promoter }\end{array}$ & $7.95 \mathrm{E}^{-04}$ & $\begin{array}{l}\text { TNF, PRRX1, ZEB2, AURKB, ZBTB16, TGFB1, CCNE1, } \\
\text { EZR, NR1D1, SOX18, CRY1, TBX6, ISL1, PROX2, } \\
\text { JUNB, NKX6-1, SHOX2, HHEX, ATF3, BTG2, PLK1, } \\
\text { IRF2BPL, TRPS1, BCL6B, NELFE, NFIA, CRYM }\end{array}$ \\
\hline GO BP & GO:0051301 cell division & $1.34 \mathrm{E}^{-03}$ & $\begin{array}{l}\text { ITGB3BP, SPC25, CDK1, CCNE1, CHMP1B, DSN1, } \\
\text { NUF2, CENPW, MAPRE2, CCNG1, WEE1 }\end{array}$ \\
\hline GO BP & $\begin{array}{l}\text { GO:0032496 response to } \\
\text { lipopolysaccharide }\end{array}$ & $1.50 \mathrm{E}^{-03}$ & $\begin{array}{l}\text { FOS, SLC11A1, TNFRSF11B, PLA2G4A, PTGER2, } \\
\text { TNF, RELT, NCF2, SERPINE1, ACP5, C2, LOXL1, } \\
\text { JUNB, TRIB1 }\end{array}$ \\
\hline GO BP & $\begin{array}{l}\text { GO:0030198 extracellular matrix } \\
\text { organization }\end{array}$ & $1.67 \mathrm{E}^{-03}$ & $\begin{array}{l}\text { COL18A1, TNFRSF11B, TNF, ADAMTSL2, OLFML2B, } \\
\text { TGFBI, NID1, POSTN }\end{array}$ \\
\hline GO BP & GO:0001755 neural crest cell migration & $1.69 \mathrm{E}^{-03}$ & ERBB4, SEMA3D, ZEB2, ISL1, HTR2B, GDNF \\
\hline GO BP & $\begin{array}{l}\text { GO:0045880 positive regulation of } \\
\text { smoothened signaling pathway }\end{array}$ & $1.83 \mathrm{E}^{-03}$ & SHOX2, SCUBE3, PRRX1, GAS1, POR \\
\hline GO BP & GO:0030316 osteoclast differentiation & $2.07 \mathrm{E}^{-03}$ & TF, TNF, ACP5, DCSTAMP, JUNB \\
\hline GO BP & GO:0002062 chondrocyte differentiation & $8.72 \mathrm{E}^{-03}$ & SHOX2, TRPS1, TGFBI, CYTL1, TGFB 1 \\
\hline GO BP & GO:0001889 liver development & $1.47 \mathrm{E}^{-02}$ & AFP, CCNE1, HHEX, COBL, BAAT, HMGCS2, DBP, TK1 \\
\hline GO BP & GO:0007623 circadian rhythm & $2.06 \mathrm{E}^{-02}$ & DHX9, TNF, NR1D1, DBP, NTRK2, CRY1, TPH1 \\
\hline GO BP & $\begin{array}{l}\text { GO:0045944 positive regulation of } \\
\text { transcription from RNA polymerase II } \\
\text { promoter }\end{array}$ & $2.50 \mathrm{E}^{-02}$ & $\begin{array}{l}\text { TNF, HEXB, PRRX1, CYTL1, FSTL3, ZEB2, GDNF, } \\
\text { TGFB1, HSPH1, SLC11A1, FOS, TEF, SOX18, TBX6, } \\
\text { CCNH, NR4A1, ISL1, MECOM, PROX2, JUNB, SHOX2, } \\
\text { HHEX, ATF3, IRF2BPL, DBP, TRPS1, NELFE, NFIA }\end{array}$ \\
\hline GO BP & GO:0001525 angiogenesis & $4.50 \mathrm{E}^{-02}$ & $\begin{array}{l}\text { COL18A1, SERPINE1, TGFBI, APOLD1, SOX18, } \\
\text { PLXND1, EPHB3, THY1 }\end{array}$ \\
\hline GO BP & $\begin{array}{l}\text { GO:0042542 response to hydrogen } \\
\text { peroxide }\end{array}$ & $4.94 \mathrm{E}^{-02}$ & CDK1, PLA2G4A, DUSP1, ERBB4, MB \\
\hline \multirow[t]{5}{*}{ GO MF } & $\begin{array}{l}\text { GO:0042803 protein homodimerization } \\
\text { activity }\end{array}$ & $6.49 \mathrm{E}^{-04}$ & $\begin{array}{l}\text { CADM3, ERBB4, HEXB, ZBTB16, GREM2, GDNF, } \\
\text { TGFB1, SLC11A1, ADH1, FAP, ALOX5AP, TEF, CIB2, } \\
\text { ZFP423, TESC, OLFML2B, ERP29, EPHX2, FZD1, } \\
\text { NR4A1, MECOM, HHEX, C1QB, PPP1R9A, ATF3, } \\
\text { NTRK2, CTSE, CRYM }\end{array}$ \\
\hline & GO:0005515 protein binding & $2.81 \mathrm{E}^{-03}$ & $\begin{array}{l}\text { COBL, ERBB4, KCNAB1, WASF1, KCNA2, CACNB3, } \\
\text { ZBTB16, CDH2, RAB3IP, SDC3, FOS, EZR, HSPA2, } \\
\text { NR1D1, ARPC2, SCG3, GUCY1A2, DNAJA1, C2, VMP1, } \\
\text { HSPA8, SCN10A, NGEF, CDK1, RAB8B, KCNB1, ERP29, } \\
\text { FZD1, NR4A1, NID1, ISL1, THY1, SH3BP5, RT1-A2, } \\
\text { EPHA4, PPP1R9A, BTG2, NTRK2, FABP1, ALOX5, } \\
\text { MAP6, HTR2B, NFIA }\end{array}$ \\
\hline & GO:0005525 GTP binding & $5.84 \mathrm{E}^{-03}$ & $\begin{array}{l}\text { TF, RAB8B, GBP5, GIMAP6, GIMAP8, RRAD, NPR2, } \\
\text { RRAGD, GNAT2, RND3, RAB19, RAC3, GUCY1A2, } \\
\text { RAB15, RAB26 }\end{array}$ \\
\hline & GO:0050840 extracellular matrix binding & $1.06 \mathrm{E}^{-02}$ & OLFML2B, TGFBI, NID1, SPP1 \\
\hline & $\begin{array}{l}\text { GO:0046982 protein heterodimerization } \\
\text { activity }\end{array}$ & $1.50 \mathrm{E}^{-02}$ & $\begin{array}{l}\text { ZFP423, CD3G, CD3E, KCNB1, HEXB, CRLF1, FZD1, } \\
\text { NR4A1, RRAGD, TGFB1, FOS, ATF3, ALOX5AP, TEF, } \\
\text { GUCY1A2, ADRA1A, CENPW, SOX18 }\end{array}$ \\
\hline
\end{tabular}


Table V. Continued.

\begin{tabular}{|c|c|c|c|}
\hline Category & Term & P-value & Genes \\
\hline \multirow[t]{5}{*}{$\mathrm{GO} \mathrm{CC}$} & GO:0005615 extracellular space & $9.32 \mathrm{E}^{-06}$ & $\begin{array}{l}\text { TF, DHH, TNF, LTBP2, IGFBP7, HEXB, PLBD1, } \\
\text { SERPINB1A, CCL9, FSTL3, ACP5, POSTN, GREM2, } \\
\text { GDNF, TGFB1, CHIT1, MTHFD2, TNFRSF11B, PTGIS, } \\
\text { EZR, ALB, SERPINA5, FAP, SERPINE1, TGFBI, } \\
\text { SEMA3D, C2, CES1C, HSPA8, SPP1, DPT, WNT8B, } \\
\text { COL18A1, CPA6, PRG4, IL9, MGP, CLIC1, SOD3, AFP, } \\
\text { CBLN2, F5, IRF2BPL, CPXM1, ALOX5, UBB }\end{array}$ \\
\hline & GO:0031012 extracellular matrix & $1.48 \mathrm{E}^{-04}$ & $\begin{array}{l}\text { COL18A1, LTBP2, IGFBP7, CKAP4, MGP, NID1, POSTN, } \\
\text { TGFB1, SOD3, CFP, TGFBI, SERPINE1, LOXL1, } \\
\text { CLEC14A, DPT }\end{array}$ \\
\hline & GO:0070062 extracellular exosome & $1.59 \mathrm{E}^{-04}$ & $\begin{array}{l}\text { LTBP2, IGFBP7, HEXB, TSPAN6, TSPAN8, HSPH1, DES, } \\
\text { SLC2A5, SERPINA5, SERPINE1, TGFBI, SCN10A, MB, } \\
\text { PTPRJ, DBNL, CDK1, PTPRF, ERP29, MGP, PRKCH, } \\
\text { CLIC1, THY1, C1QB, RND3, CHMP1B, DHRS4, BTG2, } \\
\text { RELT, RAB19, CTSE, RAB15, UBB, TNFAIP3, AKR1D1, } \\
\text { TF, ECH1, SERPINB1A, ACP5, CDH2, GIPC2, ITM2C, } \\
\text { EZR, HSPA2, ARPC2, ALB, RAC3, DNAJA1, C2, NDRG2, } \\
\text { HSPA8, SPP1, ARHGDIB, DPT, COL18A1, RAB8B, } \\
\text { CPPED1, CKAP4, EPHX2, NID1, TMBIM1, RACGAP1, } \\
\text { ANXA4, SOD3, NKX6-1, LYVE1, TMEM8A, HEBP1, } \\
\text { MYH11, FABP1, CRYM, CLEC14A }\end{array}$ \\
\hline & GO:0005604 basement membrane & $2.12 \mathrm{E}^{-04}$ & $\begin{array}{l}\text { COL18A1, TF, LAMC3, ALB, TGFBI, NTN4, NID1, } \\
\text { LOXL1, COL4A5 }\end{array}$ \\
\hline & GO:0030027 lamellipodium & $3.81 \mathrm{E}^{-04}$ & $\begin{array}{l}\text { DBNL, TESC, PPP1R9A, MYO10, WASF1, KCNA2, FAP, } \\
\text { CDH2, ARAP3, PLXND1, RAB3IP }\end{array}$ \\
\hline KEGG & rno04010:MAPK signaling pathway & $3.86 \mathrm{E}^{-03}$ & $\begin{array}{l}\text { TNF, NR4A1, CACNB3, FGF13, MECOM, TGFB1, FOS, } \\
\text { PLA2G4A, HSPA2, DUSP1, NTRK2, GADD45A, HSPA8 }\end{array}$ \\
\hline KEGG & $\begin{array}{l}\text { rno04610:Complement and coagulation } \\
\text { cascades }\end{array}$ & $1.22 \mathrm{E}^{-02}$ & C1QB, F10, F5, SERPINA5, SERPINE1, C2 \\
\hline KEGG & $\begin{array}{l}\text { rno05142:Chagas disease (American } \\
\text { trypanosomiasis) }\end{array}$ & $1.69 \mathrm{E}^{-02}$ & C1QB, FOS, CD3G, TNF, CD3E, SERPINE1, TGFB1 \\
\hline KEGG & rno04110:Cell cycle & $3.54 \mathrm{E}^{-02}$ & CDK1, CCNE1, CCNH, PLK1, GADD45A, WEE1, TGFB1 \\
\hline KEGG & rno04380:Osteoclast differentiation & $3.78 \mathrm{E}^{-02}$ & FOS, TNFRSF11B, TNF, NCF2, ACP5, JUNB, TGFB1 \\
\hline KEGG & $\begin{array}{l}\text { rno04612:Antigen processing and } \\
\text { presentation }\end{array}$ & $3.89 \mathrm{E}^{-02}$ & RT1-A2, TNF, HSPA2, RT1-CE4, RT1-M2, HSPA8 \\
\hline KEGG & $\begin{array}{l}\text { rno04141:Protein processing in } \\
\text { endoplasmic reticulum }\end{array}$ & $4.30 \mathrm{E}^{-02}$ & $\begin{array}{l}\text { HSPH1, HSPA2, CKAP4, ERP29, DNAJA1, DDOST, } \\
\text { SSR2, HSPA8 }\end{array}$ \\
\hline KEGG & rno04115:p53 signaling pathway & $4.53 \mathrm{E}^{-02}$ & CDK1, CCNE1, SERPINE1, CCNG1, GADD45A \\
\hline KEGG & rno04514:Cell adhesion molecules (CAMs) & $4.77 \mathrm{E}^{-02}$ & $\begin{array}{l}\text { RT1-A2, CADM3, OCLN, PTPRF, RT1-CE4, RT1-M2, } \\
\text { CDH2, SDC3 }\end{array}$ \\
\hline
\end{tabular}

BP, biological process; MF, molecular function; CC, cellular component; GO, Gene ontology; KEGG, Kyoto Encyclopedia of Genes and Genomes; SHRSP, stroke-prone spontaneously hypertensive rats.

inflammatory hypernociception induced by arthritis in the temporomandibular joint of rats by decreasing the expression of the pro-inflammatory cytokine, interleukin-1 $\beta$ (IL-1 $\beta$ ) (56). Wang et al (57) also observed that intra-articular botulinum toxin type A administration caused anti-neurogenic inflammation by blocking the infiltration of inflammatory cells (57). The tripeptide Gly-Gly-His was shown to inhibit secretion of pro-inflammatory IL-6 in fibroblasts (58). The study of Kalita et al (59) demonstrated that a combination of podophyllotoxin and rutin is a safe and effective protective agent to attenuate radiation-induced gastrointestinal injury by negatively regulating $\mathrm{NF}-\kappa \mathrm{B} / \mathrm{p} 53$ signaling (59).

In conclusion, our study has provided some preliminary evidence to suggest that Dbp, Crot and Mrpl4 may 
Table VI. Function enrichment for the genes of SHR-SHRSP shared group in the PPI network.

\begin{tabular}{|c|c|c|c|}
\hline Category & Term & P-value & Genes \\
\hline GO BP & GO:0006954 inflammatory response & $9.20 \mathrm{E}^{-05}$ & $\begin{array}{l}\text { CXCL1, BMP2, OLR1, AIF1, PTGS1, CHI3L1, EPHX2, } \\
\text { CCL19, TLR3, CX3CL1, CYP4F5, CCR5, CYP26B1, CD27 }\end{array}$ \\
\hline GO BP & GO:0006955 immune response & $1.33 \mathrm{E}^{-04}$ & $\begin{array}{l}\text { CXCL1, RT1-A2, RT1-A1, RT1-CE1, ENPP1, CCR5, IL12A, } \\
\text { RT1-CE10, IFI44L, CX3CL1, CTSS, CD27, RT1-BB }\end{array}$ \\
\hline GO BP & GO:0007631 feeding behavior & $8.99 \mathrm{E}^{-04}$ & HCRTR1, HTR1B, NPY4R, NPY1R, APLN \\
\hline GO BP & $\begin{array}{l}\text { GO:0002474 antigen processing and } \\
\text { presentation of peptide antigen via } \\
\text { MHC class I }\end{array}$ & $1.00 \mathrm{E}^{-03}$ & RT1-A2, RT1-A1, RT1-CE1, RT1-CE10, RT1-S3 \\
\hline GO BP & $\begin{array}{l}\text { GO:0055114 oxidation-reduction } \\
\text { process }\end{array}$ & $1.33 \mathrm{E}^{-03}$ & $\begin{array}{l}\text { HSD17B11, PTGR1, BMP2, CYP2D5, ALDH5A1, FADS1, } \\
\text { HSD17B13, PTGS1, RDH7, P4HA2, CYP4F5, CPOX, } \\
\text { CYP26B1, FMO3, OXNAD1, CYP8B1, BDH1, RETSAT, } \\
\text { ALOX12 }\end{array}$ \\
\hline GO BP & $\begin{array}{l}\text { GO:0001916 positive regulation of } \\
\text { T cell mediated cytotoxicity }\end{array}$ & $1.59 \mathrm{E}^{-03}$ & RT1-A2, RT1-A1, IL12A, RT1-S3 \\
\hline GO BP & GO:0032355 response to estradiol & $3.72 \mathrm{E}^{-03}$ & $\begin{array}{l}\text { CXCL1, PENK, FCGR1A, ENDOG, MAP1B, TFPI, BRCA2, } \\
\text { NPY1R, BDH1 }\end{array}$ \\
\hline GO BP & $\begin{array}{l}\text { GO:0045785 positive regulation of } \\
\text { cell adhesion }\end{array}$ & $5.49 \mathrm{E}^{-03}$ & PTPRJ, DUSP26, IL12A, CX3CL1, ALOX12 \\
\hline GO BP & GO:0007568 aging & $6.20 \mathrm{E}^{-03}$ & $\begin{array}{l}\text { CCR5, PENK, FADS1, ENDOG, PTGS1, GFRA1, EPOR, } \\
\text { NPY1R, CX3CL1, TIMP1, ALOX12 }\end{array}$ \\
\hline GO BP & $\begin{array}{l}\text { GO:0006631 fatty acid metabolic } \\
\text { process }\end{array}$ & $6.58 \mathrm{E}^{-03}$ & ACOX2, PER2, ACSF2, ACSM5, CROT \\
\hline GO BP & $\begin{array}{l}\text { GO:0007417 central nervous system } \\
\text { development }\end{array}$ & $8.57 \mathrm{E}^{-03}$ & NOG, ALDH5A1, DNER, VCAN, LIG4, ZBTB16 \\
\hline GO BP & GO:0001666 response to hypoxia & $2.00 \mathrm{E}^{-02}$ & $\begin{array}{l}\text { AJUBA, VEGFB, PLAT, BMP2, PENK, EPOR, CX3CL1, } \\
\text { CBFA2T3, AGTRAP }\end{array}$ \\
\hline GO BP & $\begin{array}{l}\text { GO:0009612 response to mechanical } \\
\text { stimulus }\end{array}$ & $4.08 \mathrm{E}^{-02}$ & ACTB, BMP2, ENDOG, MAP1B, CHI3L1 \\
\hline \multirow[t]{5}{*}{ GO MF } & GO:0042605 peptide antigen binding & $1.09 \mathrm{E}^{-03}$ & RT1-A1, RT1-CE1, RT1-CE10, RT1-S3, RT1-BB \\
\hline & GO:0005102 receptor binding & $1.83 \mathrm{E}^{-03}$ & $\begin{array}{l}\text { ACOX2, PLAT, BMP2, RT1-CE1, HFE2, EPHX2, RT1-S3, } \\
\text { HCST, TRDN, RT1-A1, RT1-CE10, CROT, TEC }\end{array}$ \\
\hline & GO:0008083 growth factor activity & $8.50 \mathrm{E}^{-03}$ & VEGFB, CXCL1, BMP2, IL12A, GDNF, TIMP1, THBS4 \\
\hline & $\begin{array}{l}\text { GO:0004829 threonine-tRNA ligase } \\
\text { activity }\end{array}$ & $3.67 \mathrm{E}^{-02}$ & TARS2, TARSL2 \\
\hline & $\begin{array}{l}\text { GO:0001602 pancreatic polypeptide } \\
\text { receptor activity }\end{array}$ & $3.67 \mathrm{E}^{-02}$ & NPY4R, NPY1R \\
\hline \multirow[t]{5}{*}{ GO CC } & GO:0005615 extracellular space & $2.96 \mathrm{E}^{-06}$ & $\begin{array}{l}\text { CXCL1, NAMPT, NOG, HFE2, ENPP1, GLDN, MST1, } \\
\text { CX3CL1, C1QC, GDNF, TIMP1, GPC2, APOA1, SERPINA5, } \\
\text { PTX3, APLN, SRGN, SPON1, THBS4, ACTB, PLAT, BMP2, } \\
\text { UCMA, IL1F10, CHI3L1, CILP, CCL19, CTSS, VEGFB, } \\
\text { PROM1, AFP, SERPINA3M, CD59, TFPI, IL12A, SEMA4B, } \\
\text { GFRA1, VCAN }\end{array}$ \\
\hline & GO:0009986 cell surface & $9.64 \mathrm{E}^{-06}$ & $\begin{array}{l}\text { PLAT, PTPRJ, ITGAL, BMP2, HFE2, ENPP1, TNMD, TLR3, } \\
\text { RT1-S3, CX3CL1, CTSS, RT1-BB, HCST, PROM1, APOA1, } \\
\text { CCR5, FOLR2, CD59, TFPI, VCAN, ROS1, CLEC5A, CD27 }\end{array}$ \\
\hline & $\begin{array}{l}\text { GO:0009897 external side of plasma } \\
\text { membrane }\end{array}$ & $3.39 \mathrm{E}^{-05}$ & $\begin{array}{l}\text { LY75, ITGAL, TRPM8, ANO1, CCL19, RT1-BB, RT1-A2, } \\
\text { CCR5, SERPINA5, FCGR1A, GFRA1, EPOR, CD27, ICOSLG }\end{array}$ \\
\hline & $\begin{array}{l}\text { GO:0042612 MHC class I protein } \\
\text { complex }\end{array}$ & $1.76 \mathrm{E}^{-04}$ & RT1-A2, RT1-A1, RT1-CE1, RT1-CE10, RT1-S3 \\
\hline & GO:0005576 extracellular region & $1.70 \mathrm{E}^{-03}$ & $\begin{array}{l}\text { HSD17B11, COL4A2, OLR1, ENPP1, HSD17B13, CTSS, } \\
\text { CX3CL1, GDNF, C1QC, TIMP1, DNASE2B, VEGFB, APOA1, } \\
\text { PENK, TFPI, VCAN, APOL11A, PLA2G2D, NMU, THBS4 }\end{array}$ \\
\hline
\end{tabular}


Table VI. Continued.

\begin{tabular}{|c|c|c|c|}
\hline Category & Term & P-value & Genes \\
\hline KEGG & rno04145:Phagosome & $1.97 \mathrm{E}^{-06}$ & $\begin{array}{l}\text { ACTB, MSR1, RT1-CE1, OLR1, CTSS, ATP6V1G1, RT1-S3, } \\
\text { RT1-BB, RT1-A2, RT1-A1, FCGR1A, ATP6V1E2, RT1-CE10, } \\
\text { RT1-N1, THBS4 }\end{array}$ \\
\hline KEGG & rno05416:Viral myocarditis & $8.38 \mathrm{E}^{-05}$ & $\begin{array}{l}\text { ACTB, RT1-A2, ITGAL, RT1-A1, RT1-CE1, RT1-CE10, } \\
\text { RT1-S3, RT1-N1, RT1-BB }\end{array}$ \\
\hline KEGG & rno05330:Allograft rejection & $1.12 \mathrm{E}^{-04}$ & $\begin{array}{l}\text { RT1-A2, RT1-A1, RT1-CE1, IL12A, RT1-CE10, RT1-S3, } \\
\text { RT1-N1, RT1-BB }\end{array}$ \\
\hline KEGG & rno04940:Type I diabetes mellitus & $1.89 \mathrm{E}^{-04}$ & $\begin{array}{l}\text { RT1-A2, RT1-A1, RT1-CE1, IL12A, RT1-CE10, RT1-S3, } \\
\text { RT1-N1, RT1-BB }\end{array}$ \\
\hline KEGG & $\begin{array}{l}\text { rno04514:Cell adhesion molecules } \\
\text { (CAMs) }\end{array}$ & $3.86 \mathrm{E}^{-04}$ & $\begin{array}{l}\text { RT1-A2, SIGLEC1, ITGAL, RT1-A1, RT1-CE1, RT1-CE10, } \\
\text { VCAN, RT1-S3, RT1-N1, ICOSLG, RT1-BB }\end{array}$ \\
\hline KEGG & rno05332:Graft-versus-host disease & $5.91 \mathrm{E}^{-04}$ & RT1-A2, RT1-A1, RT1-CE1, RT1-CE10, RT1-S3, RT1-N1, RT1-BB \\
\hline KEGG & $\begin{array}{l}\text { rno04612:Antigen processing and } \\
\text { presentation }\end{array}$ & $8.43 \mathrm{E}^{-04}$ & $\begin{array}{l}\text { RT1-A2, RT1-A1, RT1-CE1, RT1-CE10, RT1-S3, CTSS, } \\
\text { RT1-N1, RT1-BB }\end{array}$ \\
\hline KEGG & $\begin{array}{l}\text { rno05320:Autoimmune thyroid } \\
\text { disease }\end{array}$ & $1.34 \mathrm{E}^{-03}$ & RT1-A2, RT1-A1, RT1-CE1, RT1-CE10, RT1-S3, RT1-N1, RT1-BB \\
\hline KEGG & rno05168:Herpes simplex infection & $2.21 \mathrm{E}^{-03}$ & $\begin{array}{l}\text { RT1-A2, RT1-A1, RT1-CE1, CSNK2A1, PER2, IL12A, RT1-CE10, } \\
\text { TLR3, RT1-S3, RT1-N1, RT1-BB }\end{array}$ \\
\hline KEGG & $\begin{array}{l}\text { rno04610: Complement and } \\
\text { coagulation cascades }\end{array}$ & $5.57 \mathrm{E}^{-03}$ & PLAT, C1QA, CD59, SERPINA5, TFPI, C1QC \\
\hline KEGG & rno00650:Butanoate metabolism & $9.57 \mathrm{E}^{-03}$ & HMGCS2, ALDH5A1, BDH1, ACSM5 \\
\hline KEGG & $\begin{array}{l}\text { rno05150:Staphylococcus aureus } \\
\text { infection }\end{array}$ & $1.04 \mathrm{E}^{-02}$ & C1QA, ITGAL, FCGR1A, C1QC, RT1-BB \\
\hline KEGG & $\begin{array}{l}\text { rno05169:Epstein-Barr virus } \\
\text { infection }\end{array}$ & $3.01 \mathrm{E}^{-02}$ & RT1-A2, ITGAL, RT1-A1, RT1-CE1, RT1-CE10, RT1-S3, RT1-N1 \\
\hline
\end{tabular}

BP, biological process; MF, molecular function; CC, cellular component; GO, Gene ontology; KEGG, Kyoto encyclopedia of genes and genomes. SHR, spontaneously hypertensive rats; SHRSP, stroke-prone SHR rats.

Table VII. Candidate small-molecule drugs.

\begin{tabular}{lcc}
\hline CMAP name & Enrichment & P-value \\
\hline Betulin & -0.96 & $2.20 \mathrm{E}^{-04}$ \\
Gly-His-Lys & -0.93 & $5.40 \mathrm{E}^{-04}$ \\
Benzathine Benzylpenicillin & -0.90 & $1.60 \mathrm{E}^{-04}$ \\
Prestwick-1103 & -0.89 & $4.00 \mathrm{E}^{-04}$ \\
PF-00539745-00 & -0.88 & $3.43 \mathrm{E}^{-03}$ \\
Quinostatin & -0.88 & $2.99 \mathrm{E}^{-02}$ \\
5279552 & -0.86 & $3.77 \mathrm{E}^{-02}$ \\
Podophyllotoxin & -0.86 & $7.00 \mathrm{E}^{-04}$ \\
Cefuroxime & 0.80 & $3.00 \mathrm{E}^{-03}$ \\
STOCK1N-35215 & 0.81 & $1.37 \mathrm{E}^{-02}$ \\
NS-398 & 0.91 & $1.38 \mathrm{E}^{-02}$ \\
\hline
\end{tabular}

be potential targets for treatment of SHRSP. Their expression may be reversed by miRNAs (rno-miR-126a-5p and rno-miR-31a) or small-molecule drugs (botulin, Gly-His-Lys and podophyllotoxin). However, further in vitro and in vivo experiments are required in order to confirm these conclusions.

\section{Acknowledgements \\ Not applicable. \\ Funding \\ No funding was received. \\ Availability of data and materials \\ The sequencing data GSE41452, GSE31457, GSE41453, GSE53363 and GSE53361 were downloaded from the GEO database in NCBI (http://www.ncbi.nlm.nih.gov/geo/).}

\section{Authors' contributions}

QZ and LW conceived the design of the original study. QZ and HS conducted the statistical analysis. LY was involved with the interpretation of the data. QZ drafted the manuscript. LW participated in critical revisions of the 
manuscript. All authors approved the final version of the manuscript.

\section{Ethics approval and consent to participate}

Not applicable.

\section{Patient consent for publication}

Not applicable.

\section{Competing interests}

The authors declare that they have no competing interests.

\section{References}

1. Kim IG, So WY and Sung DJ: The relationships between lifestyle factors and hypertension in community-dwelling Korean adults. J Phys Ther Sci 27: 3689-3692, 2015.

2. Kupferman JC, Zafeiriou DI, Lande MB, Kirkham FJ and Pavlakis SG: Stroke and hypertension in children and adolescents. J Child Neurol 32: 408-417, 2017.

3. Alloubani A, Saleh A and Abdelhafiz I: Hypertension and diabetes mellitus as a predictive risk factors for stroke. Diabetes Metab Syndr 12: 577-584, 2018.

4. Shambesh MKA, Emahbes TM, Saleh ZE, Elosta MAA and Shambesh IM: Role of hypertension as a major risk factor of stroke in Africa; Libya: Community based survey. British J Medicine Med Res 9: 1-11, 2015.

5. Adil MM, Beslow LA, Qureshi AI, Malik AA and Jordan LC: Hypertension is associated with increased mortality in children hospitalized with arterial ischemic stroke. Pediatr Neurol 56 25-29, 2016.

6. Wang W, Jiang B, Sun H, Ru X, Sun D, Wang L, Wang L, Jiang Y, Li Y, Wang Y, et al: Prevalence, incidence, and mortality of stroke in China: Results from a nationwide population-based survey of 480687 adults. Circulation 135: 759-771, 2017.

7. McGrath R, Markides K, Hall O and Peterson M: The burden of health conditions for middle-aged and older adults in the United States: Disability-adjusted life years. BMC Geriatr 19: $100,2019$.

8. Rubattu S, Cotugno M, Bianchi F, Sironi L, Gelosa P, Stanzione R, Forte M, De Sanctis C, Madonna M, Marchitti S, et al: A differential expression of uncoupling protein-2 associates with renal damage in stroke-resistant spontaneously hypertensive rat/stroke-prone spontaneously hypertensive rat-derived stroke congenic lines. J Hypertens 35: 1857-1871, 2017.

9. Lan C, Chen X, Zhang Y, Wang W, Wang WE, Liu Y, Cai Y, Ren $\mathrm{H}$, Zheng S and Zhou L and Zeng C: Curcumin prevents strokes in stroke-prone spontaneously hypertensive rats by improving vascular endothelial function. BMC Cardiovasc Disord 18: 43, 2018.

10. Yoshida M, Watanabe Y, Yamanishi K, Yamashita A, Yamamoto H, Okuzaki D, Shimada K, Nojima H, Yasunaga T, Okamura $\mathrm{H}$, et al: Analysis of genes causing hypertension and stroke in spontaneously hypertensive rats: gene expression profiles in the brain. Int J Mol Med 33: 887-896, 2014.

11. Yamamoto H, Okuzaki D, Yamanishi K, Xu Y, Watanabe Y, Yoshida M, Yamashita A, Goto N, Nishiguchi S, Shimada K, et al: Genetic analysis of genes causing hypertension and stroke in spontaneously hypertensive rats. Int J Mol Med 31: 1057-1065, 2013.

12. Watanabe $Y$, Yoshida M, Yamanishi $K$, Yamamoto $H$, Okuzaki D, Nojima H, Yasunaga T, Okamura H, Matsunaga H and Yamanishi H: Genetic analysis of genes causing hypertension and stroke in spontaneously hypertensive rats: Gene expression profiles in the kidneys. Int J Mol Med 36: 712-724, 2015.

13. Palao T, Swärd K, Jongejan A, Moerland PD, de Vos J, van Weert A, Arribas SM, Groma G, vanBavel E and Bakker EN Gene expression and MicroRNA expression analysis in small arteries of spontaneously hypertensive rats. Evidence for ER stress. PLoS One 10: e0137027, 2015.
14. Nemoto K, Ikeda A, Ito S, Miyata M, Yoshida C and Degawa M: Comparison of constitutive gene expression levels of hepatic cholesterol biosynthetic enzymes between Wistar-Kyoto and stroke-prone spontaneously hypertensive rats. Biol Pharm Bull 36: 1216-1220, 2013.

15. Rubattu S, Stanzione R, Bianchi F, Cotugno M, Forte M, Ragione FD, Fioriniello S, D'Esposito M, Marchitti S, Madonna M, et al: Reduced brain UCP2 expression mediated by microRNA-503 contributes to increased stroke susceptibility in the high-salt fed stroke-prone spontaneously hypertensive rat. Cell Death Dis 8: e2891, 2017.

16. Matsuoka H, Tamura A, Kinehara M, Shima A, Uda A, Tahara $\mathrm{H}$ and Michihara A: Levels of tight junction protein CLDND1 are regulated by microRNA-124 in the cerebellum of stroke-prone spontaneously hypertensive rats. Biochem Biophys Res Commun 498: 817-823, 2018.

17. Diboun I, Wernisch L, Orengo CA and Koltzenburg M: Microarray analysis after RNA amplification can detect pronounced differences in gene expression using limma. BMC Genomics 7: 252, 2006.

18. Green GH and Diggle PJ: On the operational characteristics of the benjamini and hochberg false discovery rate procedure. Stat Appl Genet Mol Biol 6: 27, 2007.

19. Szklarczyk D, Franceschini A, Wyder S, Forslund K, Heller D, Huerta-Cepas J, Simonovic M, Roth A, Santos A, Tsafou KP, et al: STRING v10: Protein-protein interaction networks, integrated over the tree of life. Nucleic Acids Res 43: D447-D452, 2015.

20. Kohl M, Wiese S and Warscheid B: Cytoscape: Software for visualization and analysis of biological networks. Methods Mol Biol 696: 291-303, 2011.

21. Dweep H and Gretz N: miRWalk2. 0: A comprehensive atlas of microRNA-target interactions. Nat Methods 12: 697, 2015.

22. Huang DW, Sherman BT and Lempicki RA: Systematic and integrative analysis of large gene lists using DAVID bioinformatics resources. Nat Protoc 4: 44-57, 2009.

23. Subramanian A, Narayan R, Corsello SM, Peck DD, Natoli TE, Lu X, Gould J, Davis JF, Tubelli AA, Asiedu JK, et al: A next generation connectivity map: L1000 platform and the first 1,000,000 Profiles. Cell 171: 1437-1452.e17, 2017.

24. Zhixiang Y, Cheng W, Jibing X, Bisheng G, Ming X and Deyu L: Ambulatory blood pressure monitoring in children suffering from orthostatic hypertension. Biomed Eng Online 17: 129, 2018.

25. Kario K, Pickering TG, Matsuo T, Hoshide S, Schwartz JE and Shimada K: Stroke prognosis and abnormal nocturnal blood pressure falls in older hypertensives. Hypertension 38: 852-857, 2001.

26. Mateo-Gavira I, Vílchez-López FJ, García-Palacios MV, Laureano CS, Jiménez-Carmona S and Aguilar-Diosdado M: Nocturnal blood pressure is associated with the progression of microvascular complications and hypertension in patients with type 1 diabetes mellitus. J Diabetes Complications 30: 1326-1332, 2016.

27. Castilla-Guerra L, Espino-Montoro A, Fernández-Moreno MC and López-Chozas JM: Abnormal blood pressure circadian rhythm in acute ischaemic stroke: Are lacunar strokes really different? Int J Stroke 4: 257-261, 2010.

28. Yan B, Peng L, Dong Q, Zheng F, Yang P, Sun L, Gong S, Zeng L and Wang G: Reverse-dipper pattern of blood pressure may predict lacunar infarction in patients with essential hypertension. Eur J Neurol 22: 1022-1025, 2015.

29. Richards J, Diaz AN and Gumz ML: Clock genes in hypertension: novel insights from rodent models. Blood Press Monit 19: 249-254, 2014.

30. Leu HB, Chung CM, Lin SJ, Chiang KM, Yang HC, Ho HY, Ting CT, Lin TH, Sheu SH, Tsai WC, et al: Association of circadian genes with diurnal blood pressure changes and non-dipper essential hypertension: A genetic association with young-onset hypertension. Hypertens Res 38: 155-162, 2015.

31. Corella D, Asensio EM, Coltell O, Sorlí JV, Estruch R, Martínez-González MÁ, Salas-Salvadó J, Castañer O, Arós F, Lapetra $\mathrm{J}$, et al: CLOCK gene variation is associated with incidence of type-2 diabetes and cardiovascular diseases in type-2 diabetic subjects: Dietary modulation in the PREDIMED randomized trial. Cardiovasc Diabetol 15: 4, 2016.

32. Kurbatova IV, Topchieva LV, Korneva VA, Kolomeichuk SN and Nemova NN: Expression of circadian rhythm genes CLOCK, BMAL1, and PER1 in buccal epithelial cells of patients with essential arterial hypertension in dependence on polymorphic variants of CLOCK and BMAL1 genes. Bull Exp Biol Med 157: 360-363, 2014. 
33. Douma LG, Solocinski K, Holzworth MR, Crislip GR Masten SH, Miller AH, Cheng KY, Lynch IJ, Cain BD, Wingo CS and Gumz ML: Female C57BL/6J mice lacking the circadian clock protein PER1 are protected from nondipping hypertension. Am J Physiol Regul Integr Comp Physiol 316: R50-R 58, 2019.

34. Alli AA, Yu L, Holzworth M, Richards J, Cheng KY, Lynch IJ, Wingo CS and Gumz ML: Direct and indirect inhibition of the circadian clock protein PER1: Effects on ENaC and blood pressure. Am J Physiol Renal Physiol 316: F807-F813, 2019.

35. Lembach A, Stahr A, Ali AAH, Ingenwerth $M$ and von Gall C: Sex-dependent effects of bmal1-deficiency on mouse cerebral cortex infarction in response to photothrombotic stroke. Int J Mol Sci 19: pii: E3124, 2018

36. Yoshiro N, Takeshi T, Daizo K, Takahiro O, Shinji M, Miho M, Tsuyoshi S, Yoshio F, Mitsumasa O and Tadaaki I: Circadian gene expression of clock genes and plasminogen activator inhibitor-1 in heart and aorta of spontaneously hypertensive and Wistar-Kyoto rats. J Hypertens 21: 1107-1115, 2003

37. Jin $\mathrm{F}$ and Xing J: Circulating miR-126 and miR-130a levels correlate with lower disease risk, disease severity, and reduced inflammatory cytokine levels in acute ischemic stroke patients. Neurol Sci 39: 1757-1765, 2018.

38. Jin F and Xing J: Circulating pro-angiogenic and anti-angiogenic microRNA expressions in patients with acute ischemic stroke and their association with disease severity. Neurol Sci 38: 2015-2023, 2017.

39. Geng W, Tang H, Luo S, Lv Y, Liang D, Kang X and Hong W: Exosomes from miRNA-126-modified ADSCs promotes functional recovery after stroke in rats by improving neurogenesis and suppressing microglia activation. Am J Transl Res 11: 780-792, 2019.

40. Pan Q, Zheng J, Du D, Liao X, Ma C, Yang Y, Chen Y, Zhong W and Ma X: MicroRNA-126 priming enhances functions of endothelial progenitor cells under physiological and hypoxic conditions and their therapeutic efficacy in cerebral ischemic damage. Stem Cells Int 2018: 2912347, 2018.

41. Vega-Badillo J, Gutiérrez-Vidal R, Hernández-Pérez HA, Villamil-Ramírez H, León-Mimila $\mathrm{P}$, Sánchez-Muñoz F, Morán-Ramos S, Larrieta-Carrasco E, Fernández-Silva I, Méndez-Sánchez N, et al: Hepatic miR-33a/miR-144 and their target gene ABCA1 are associated with steatohepatitis in morbidly obese subjects. Liver Int 36: 1383-1391, 2016.

42. Rottiers V and Näär AM: MicroRNAs in metabolism and metabolic disorders. Nat Rev Mol Cell Biol 13: 239-250, 2012.

43. Kim S, Sohn I, Lee YS and Lee YS: Hepatic gene expression profiles are altered by genistein supplementation in mice with diet-induced obesity. J Nutr 135: 33-41, 2005.

44. Roush GC: Obesity-induced hypertension: Heavy on the accelerator. J Am Heart Assoc 8: e012334, 2019.

45. Mitchell AB, Cole JW, McArdle PF, Cheng YC, Ryan KA, Sparks MJ, Mitchell BD and Kittner SJ: Obesity increases risk of ischemic stroke in young adults. Stroke 46: 1690-1692, 2015.

46. Irwin DC, Garat CV, Crossno JT Jr, Maclean PS, Sullivan TM, Erickson PF, Jackman MR, Harral JW, Reusch JEB and Klemm DJ: Obesity-related pulmonary arterial hypertension in rats correlates with increased circulating inflammatory cytokines and lipids and with oxidant damage in the arterial wall but not with hypoxia. Pulm Circ 4: 638-653, 2014.

47. Maysami S, Haley MJ, Gorenkova N, Krishnan S, McColl BW and Lawrence CB: Prolonged diet-induced obesity in mice modifies the inflammatory response and leads to worse outcome after stroke. J Neuroinflammation 12: 140, 2015.
48. Ulu A, Harris TR, Morisseau C, Miyabe C, Inoue H, Schuster G, Dong H, Iosif AM, Liu JY, Weiss RH, et al: Anti-inflammatory effects of $\omega-3$ polyunsaturated fatty acids and soluble epoxide hydrolase inhibitors in angiotensin-II-dependent hypertension. J Cardiovasc Pharmacol 62: 285-297, 2013.

49. Xu N, Meisgen F, Butler LM, Han G, Wang XJ, SöderbergNauclér C, Ståhle M, Pivarcsi A and Sonkoly E: MicroRNA-31 is overexpressed in psoriasis and modulates inflammatory cytokine and chemokine production in keratinocytes via targeting serine/threonine kinase 40. J Immunol 190: 678-688, 2013.

50. Benita Y, Kikuchi H, Smith AD, Zhang MQ, Chung DC and Xavier RJ: An integrative genomics approach identifies Hypoxia Inducible Factor-1 (HIF-1)-target genes that form the core response to hypoxia. Nucleic Acids Res 37: 4587-4602, 2009.

51. Ritz MF, Fluri F, Engelter ST, Schaeren-Wiemers N and Lyrer PA: Cortical and putamen age-related changes in the microvessel density and astrocyte deficiency in spontaneously hypertensive and stroke-prone spontaneously hypertensive rats. Curr Neurovasc Res 6: 279-287, 2009.

52. Liu D, Lei L, Desir M, Huang Y, Cleman J, Jiang W, FernandezHernando C, Di Lorenzo A, Sessa WC and Giordano FJ: Smooth muscle hypoxia-inducible factor $1 \alpha$ links intravascular pressure and atherosclerosis-brief report. Arterioscler Thromb Vasc Biol 36: 442-445, 2016.

53. Barteczek P, Li L, Ernst AS, Böhler LI, Marti HH and Kunze R: Neuronal HIF-1 $\alpha$ and HIF- $2 \alpha$ deficiency improves neuronal survival and sensorimotor function in the early acute phase after ischemic stroke. J Cereb Blood Flow Metab 37: 291-306, 2017.

54. Williams TF, Mirando AC, Wilkinson B, Francklyn CS and Lounsbury KM: Secreted Threonyl-tRNA synthetase stimulates endothelial cell migration and angiogenesis. Sci Rep 3: 1317, 2013.

55. Zhai ZY and Feng J: Constraint-induced movement therapy enhances angiogenesis and neurogenesis after cerebral ischemia/reperfusion. Neural Regen Res 14: 1743-1754, 2019.

56. Lora VR, Clemente-Napimoga JT, Abdalla HB, Macedo CG, Canales GT and Barbosa CM: Botulinum toxin type A reduces inflammatory hypernociception induced by arthritis in the temporomadibular joint of rats. Toxicon 129: 52-57, 2017.

57. Wang L, Wang K, Chu X, Li T, Shen N, Fan C, Niu Z, Zhang X and $\mathrm{Hu} \mathrm{L}$ : Intra-articular injection of Botulinum toxin A reduces neurogenic inflammation in CFA-induced arthritic rat model. Toxicon 126: 70-78, 2017.

58. Gruchlik A, Jurzak M, Chodurek E and Dzierzewicz Z: Effect of Gly-Gly-His, Gly-His-Lys and their copper complexes on TNF-alpha-dependent IL-6 secretion in normal human dermal fibroblasts. Acta Pol Pharm 69: 1303-1306, 2012.

59. Kalita B, Ranjan R, Singh A, Yashavarddhan MH, Bajaj S and Gupta ML: A combination of podophyllotoxin and rutin attenuates radiation induced gastrointestinal injury by negatively regulating $\mathrm{NF}-\kappa \mathrm{B} / \mathrm{p} 53$ signaling in lethally irradiated mice. PLoS One 11: e0168525, 2010.

This work is licensed under a Creative Commons Attribution-NonCommercial-NoDerivatives 4.0 International (CC BY-NC-ND 4.0) License. 